
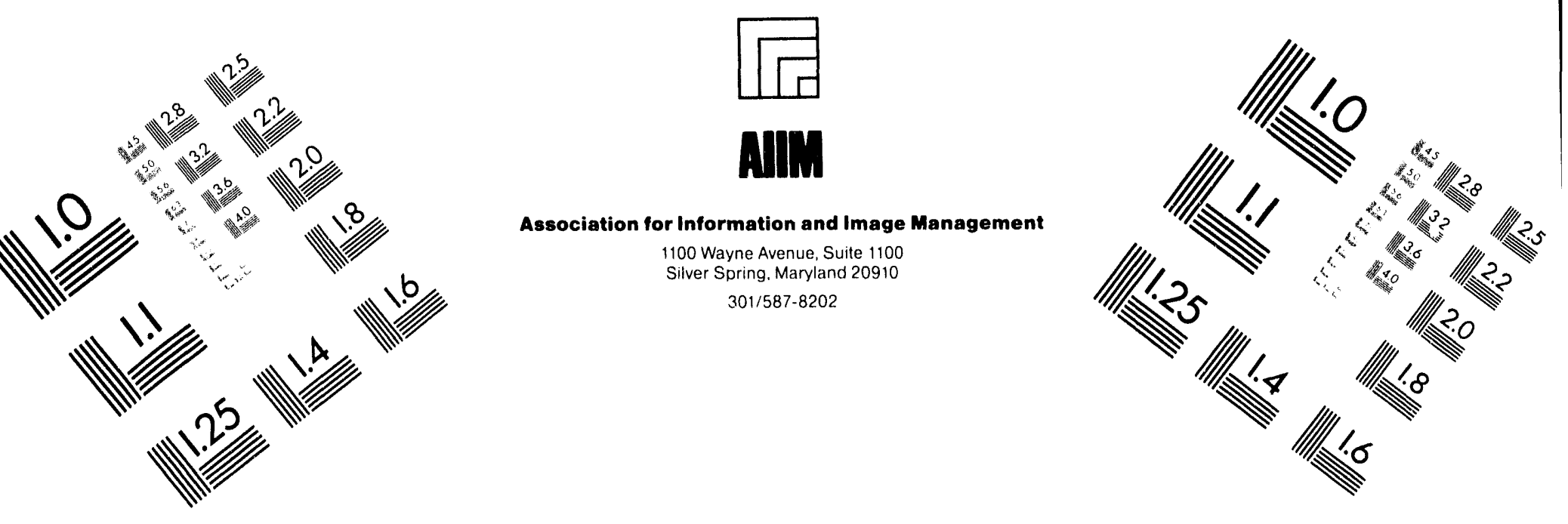

Centimeter

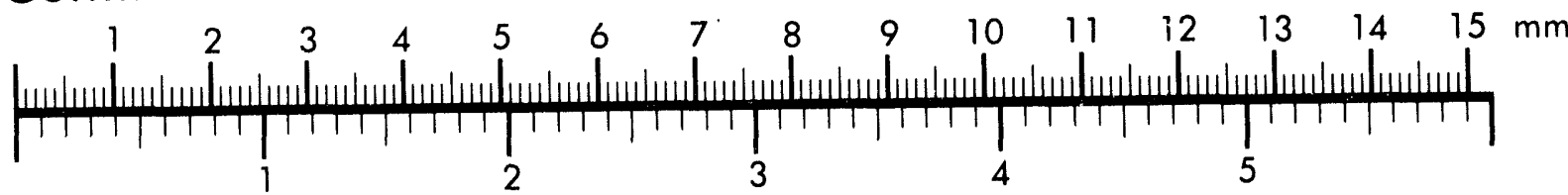

Inches
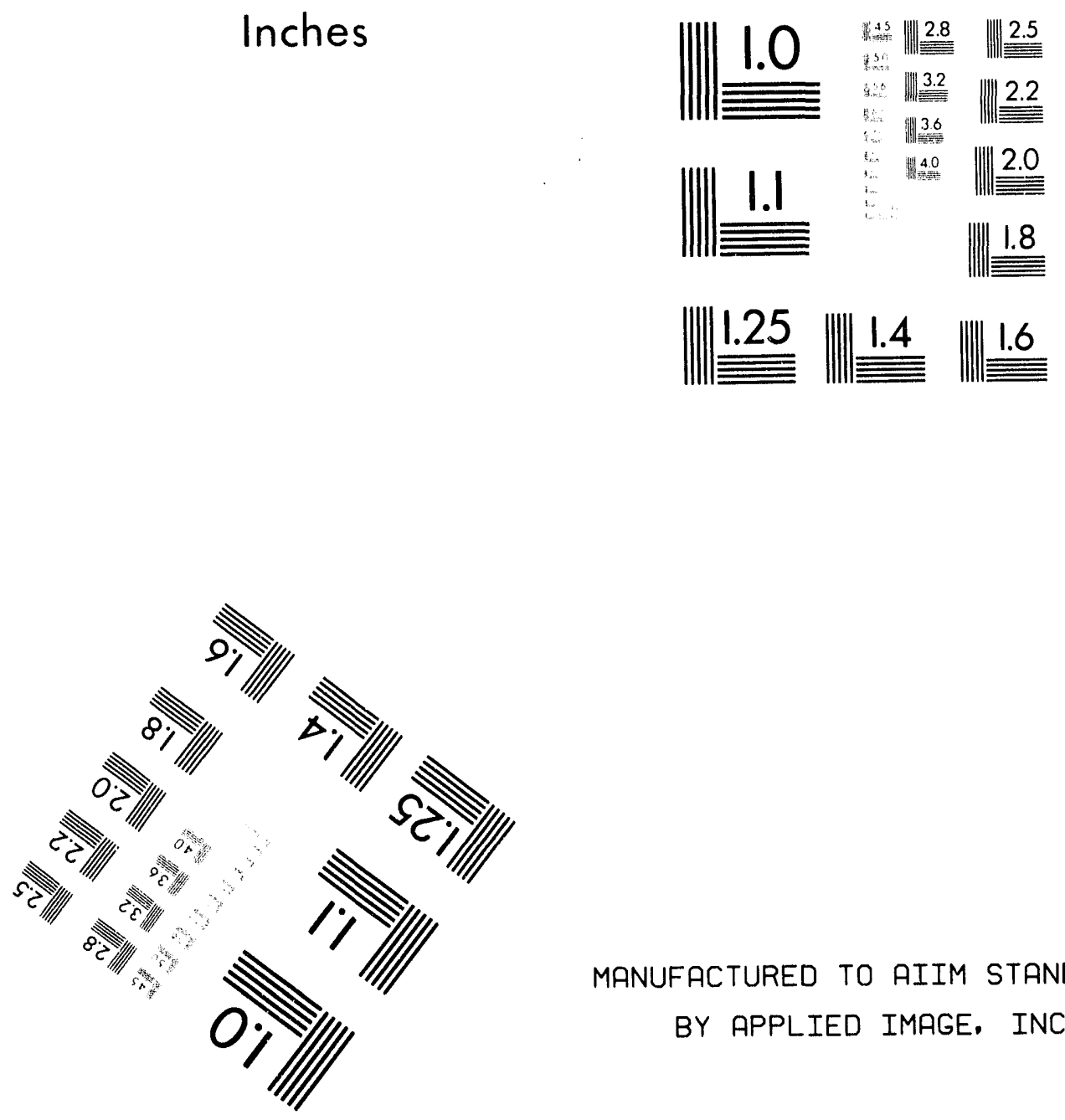

MANUFACTURED TO AIIM STANDARDS

BY APPLIED IMAGE, INC.

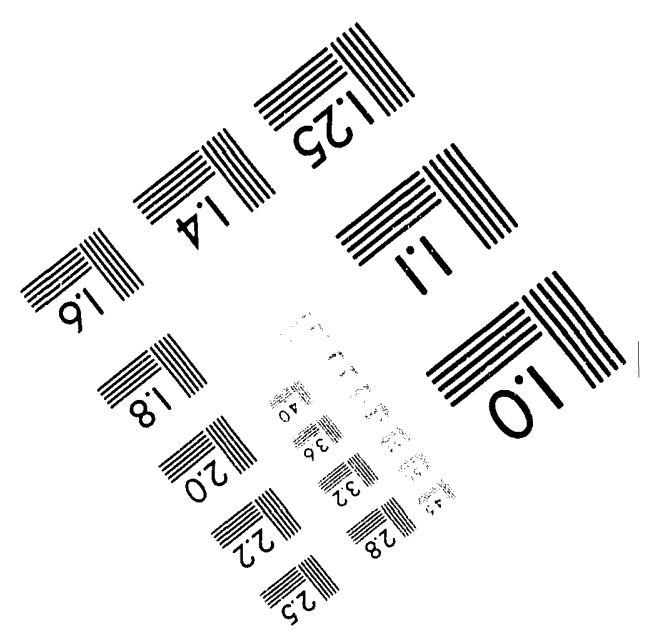



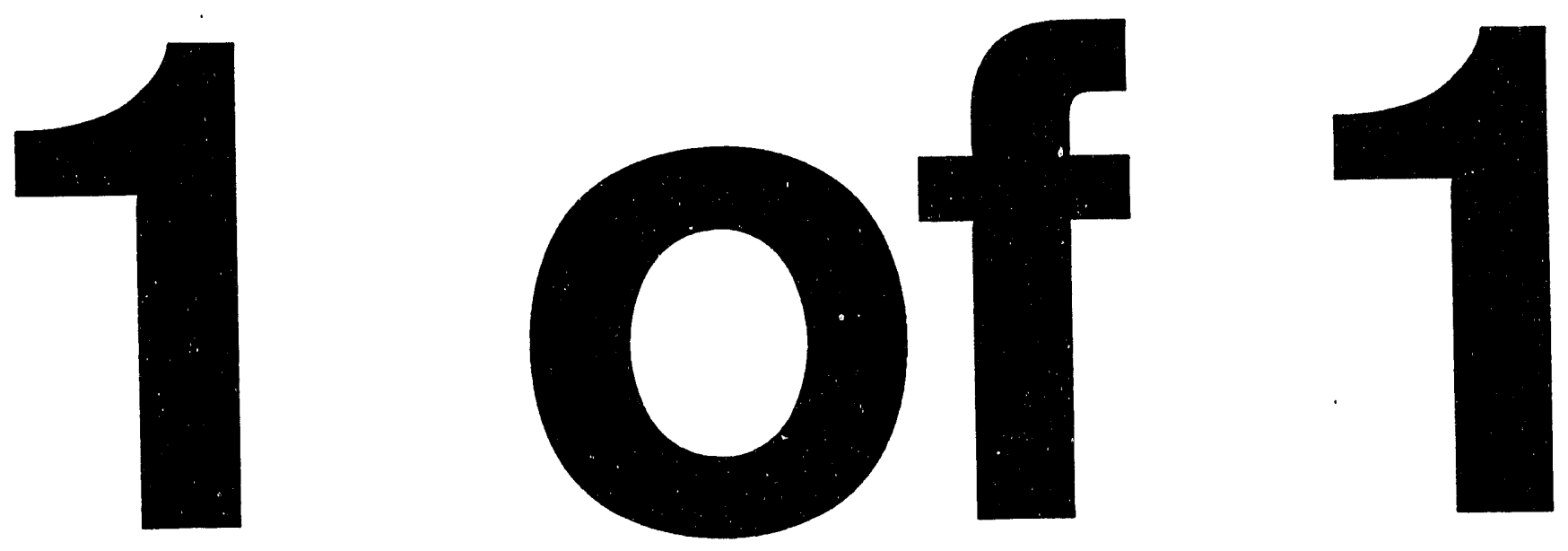
EGG-2723

Distribution Category: UC-425

\title{
Fusion Safety Program Annual Report Fiscal Year 1993
}

\author{
Glen R. Longhurst \\ Lee C. Cadwallader \\ Thomas J. Dolan \\ J. Stephen Herring \\ Kathryn A. McCarthy \\ Brad J. Merrill \\ Chester G. Motloch \\ David A. Petti
}

Published December 1993

\section{Idaho National Engineering Laboratory \\ EG\&G Idaho, Inc. Idaho Falls, Idaho 83415}

Prepared for the U.S. Department of Energy Office of Energy Research Under DOE Idaho Operations Office Contract DE-AC07-76ID01570 


\begin{abstract}
This report summarizes the major activities of the Fusion Safety Program in Fiscal Year 1993. The Idaho National Engineering Laboratory (INEL) has been designated by DOE as the lead laboratory for fusion safety, and EG\&G Idaho, Inc., is the prime contractor for INEL operations. The Fusion Safety Program was initiated in 1979. Activities are conducted at the INEL and in participating organizations, including universities and private companies. Technical areas covered in the report include tritium safety, beryllium safety, activation product release, reactions involving potential plasma-facing materials, safety of fusion magnet systems, plasma disruptions and edge physics modeling, risk assessment failure rates, computer codes for reactor transient analysis, and regulatory support. These areas include work completed in support of the International Thermonuclear Experimental Reactor (ITER). Also included in the report are summaries of the safety and environmental studies performed at the INEL for the Tokamak Physics Experiment and the Tokamak Fusion Test Reactor projects at the Princeton Plasma Physics Laboratory and a summary of the technical support for the ARIES/PULSAR commercial reactor design studies.
\end{abstract}




\section{CONTENTS}

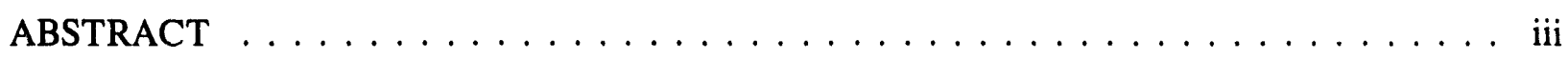

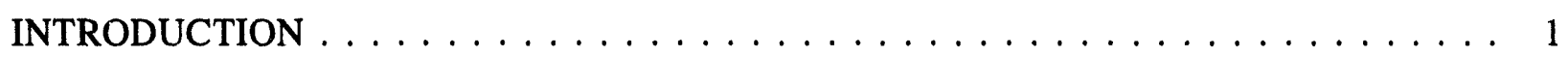

INTERNATIONAL THERMONUCLEAR EXPERIMENTAL REACTOR DESIGN AND

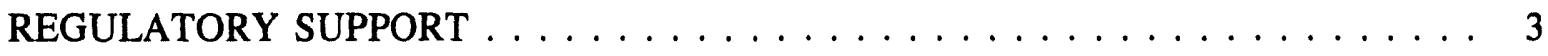

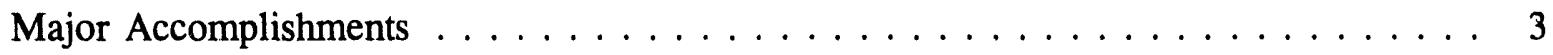

ITER Design Support $\ldots \ldots \ldots \ldots \ldots \ldots \ldots \ldots$

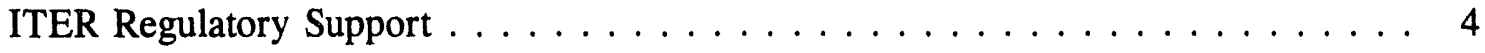

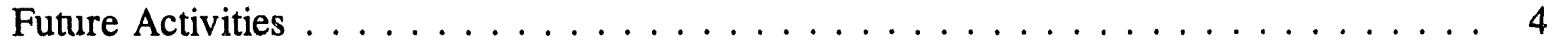

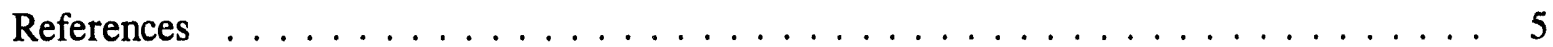

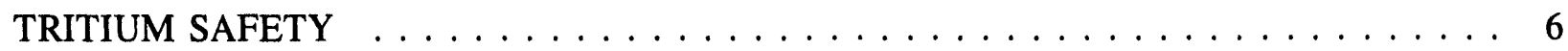

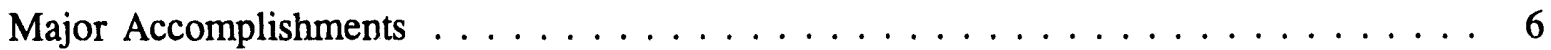

Tritium Research Laboratory . . . . . . . . . . . . . . . . . . . 6

Plasma-Driven Implantation and Permeation $\ldots \ldots \ldots \ldots \ldots$

Environmental Monitoring at TFTR $\ldots \ldots \ldots \ldots \ldots \ldots$

Tritium Plasma Experiment (TPE) $\ldots \ldots \ldots \ldots \ldots \ldots \ldots \ldots$

Inertial Confinement Fusion $\ldots \ldots \ldots \ldots \ldots \ldots$

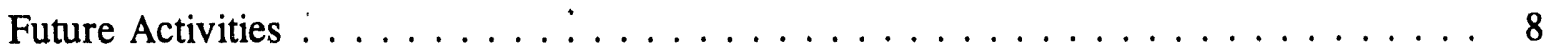

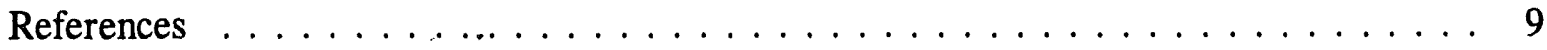

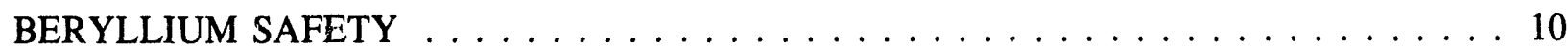

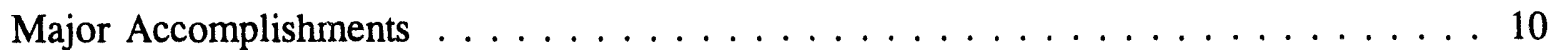

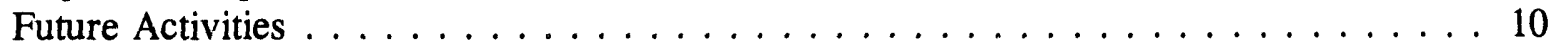

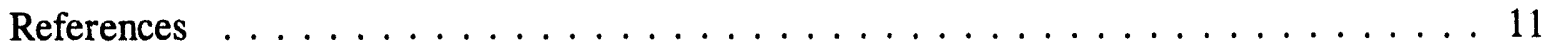

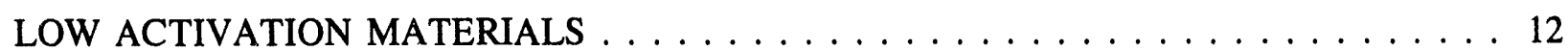

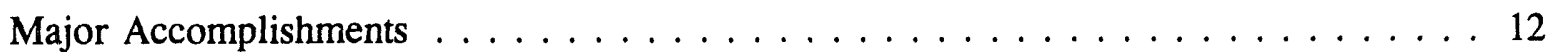

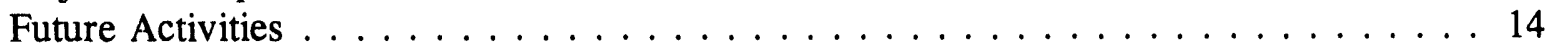

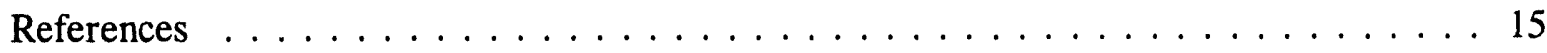

ACTIVATION PRODUCT CHEMICAL REACTIVITY, VOLATILITY, AND

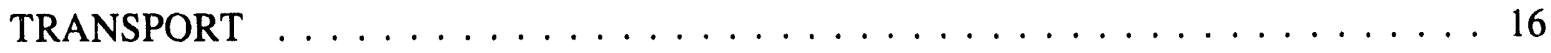

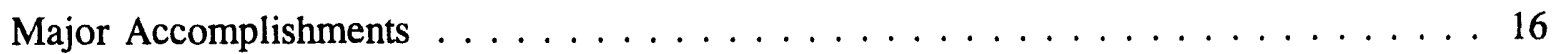

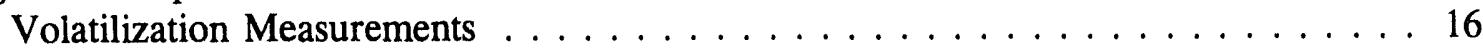

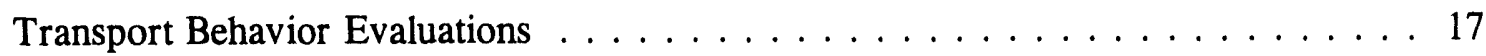

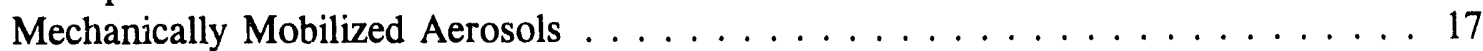

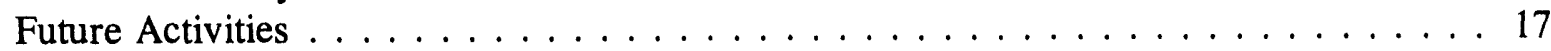

References .............................. . . . . . . . . . .

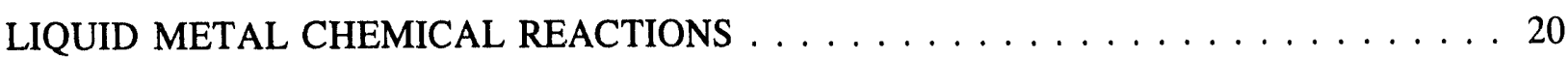

Major Accomplishments . . . . . . . . . . . . . . . . . . 20

Molten Lithium-Organic Coolant Interactions . . . . . . . . . . . . . . . . . 20 
Model of Fuel/Coolant Mixing Process $\ldots \ldots \ldots \ldots \ldots \ldots$

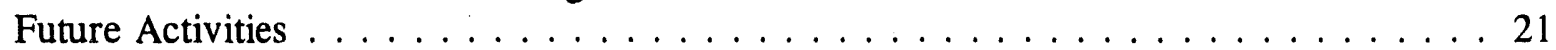

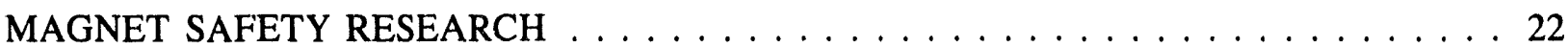

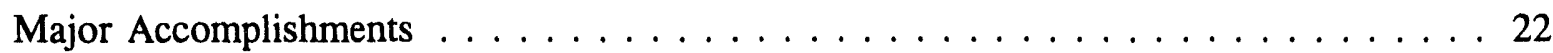

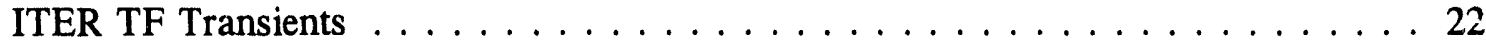

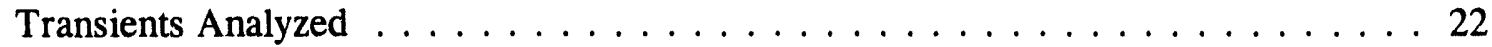

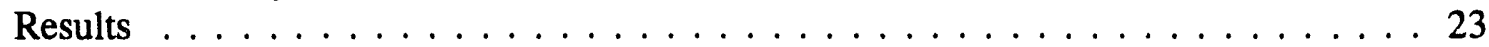

Quench Model Development . . . . . . . . . . . . . . . . 23

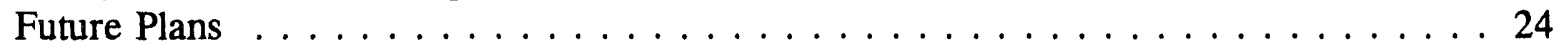

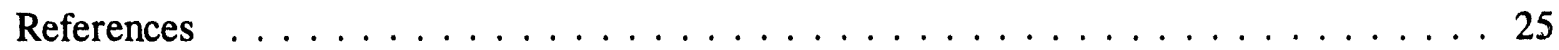

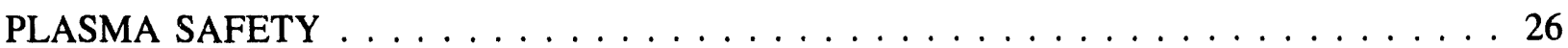

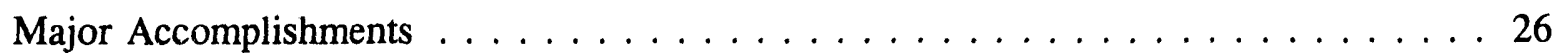

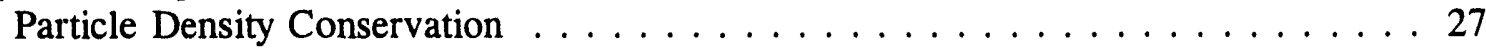

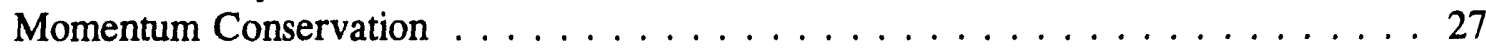

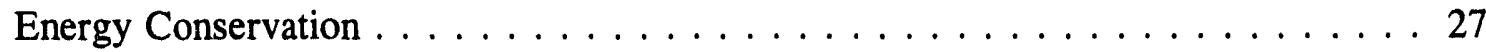

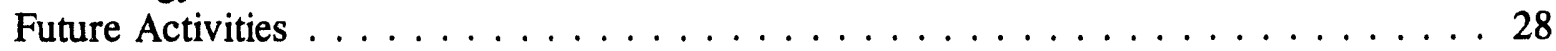

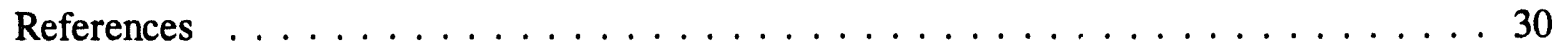

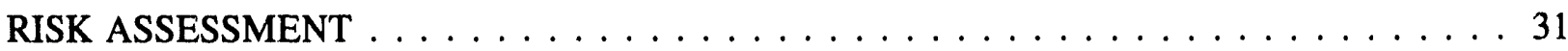

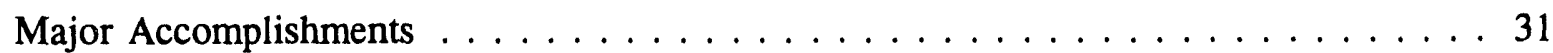

Component Failure Rates . . . . . . . . . . . . . . . . . . 31

Dose Consequence Computer Codes . . . . . . . . . . . . . . . . 31

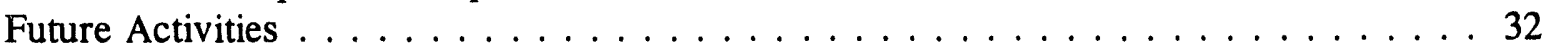

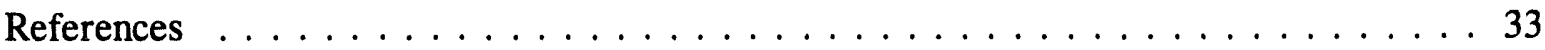

ATHENA DEVELOPMENT $\ldots \ldots \ldots \ldots \ldots \ldots \ldots \ldots \ldots \ldots \ldots \ldots \ldots$

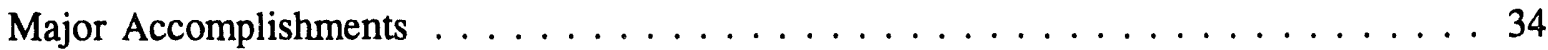

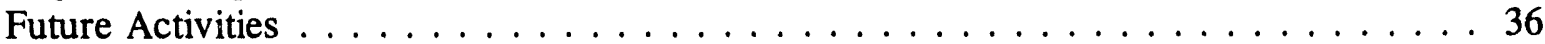

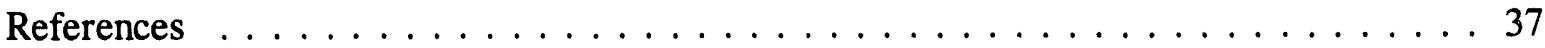

TOKAMAK PHYSICS EXPERIMENT SAFETY ANALYSES AND

ENVIRONMENTAL SAFETY \& HEALTH COMPLIANCE ACTIVITIES . . . . . . . . 38

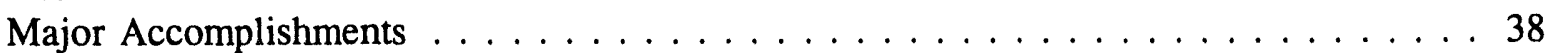

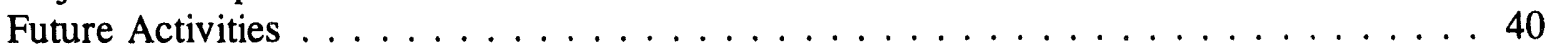

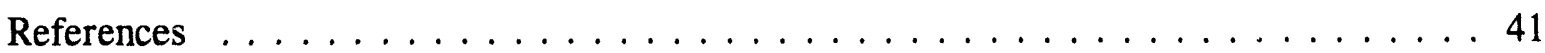

ARIES TOKAMAK REACTOR DESIGN STUDY $\ldots \ldots \ldots \ldots \ldots \ldots$

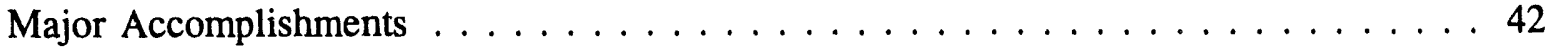

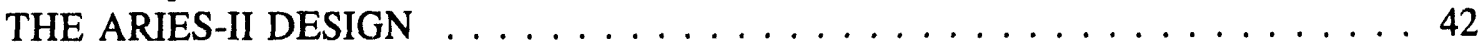

Vanadium Recycling . . . . . . . . . . . . . . . . . . . . 43

The ARIES-IV Design . . . . . . . . . . . . . . . . . . . 43

Radionuclide Inventories $\ldots \ldots \ldots \ldots \ldots \ldots$

Future Activities . . . . . . . . . . . . . . . . . . . . . . . . . 44

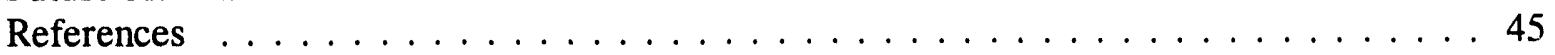


APPENDIX A-ABSTRACTS OR SUMMARIES OF FUSION SAFETY PROGRAM

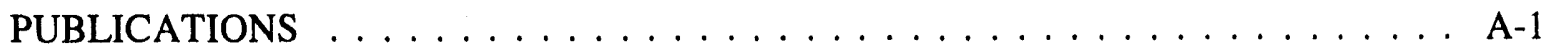

ITER Design and Regulatory Support $\ldots \ldots \ldots \ldots \ldots \ldots \ldots \ldots \ldots$

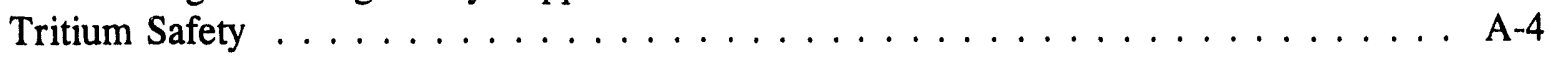

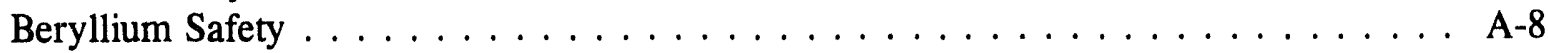

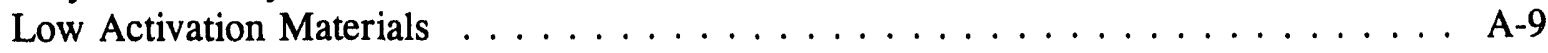

Liquid Metal Chemical Reactions . . . . . . . . . . . . . . . . A-11

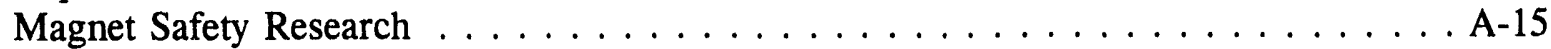

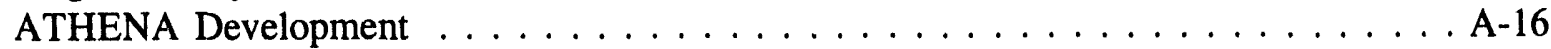

TFTR/TPX Support . . . . . . . . . . . . . . . . . . . . . . A-17

ARIES/PULSAR Tokamak Design Studies $\ldots \ldots \ldots \ldots \ldots \ldots \ldots$. . . . . . . . . .

FIGURES

1. Comparison of measured permeation rates for implanted deuterium in steel

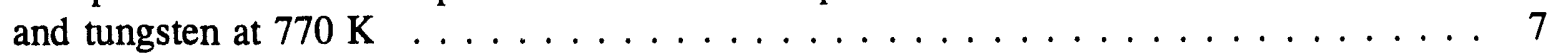

2. SEM micrograph at $2000 \mathrm{x}$ magnification showing the cross section of the plasma-sprayed tungsten coating $\ldots \ldots \ldots \ldots \ldots \ldots \ldots \ldots \ldots \ldots \ldots \ldots \ldots \ldots$

3. The INEL automatic environmental monitoring station for tritiated water $\ldots \ldots \ldots$

4. Calculated early doses at $2-\mathrm{km}$ site boundary for vanadium alloys and stainless steel

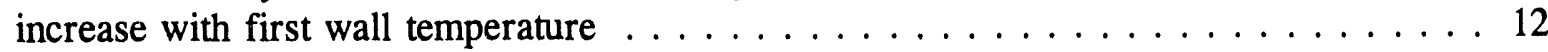

5. Early whole body dose at $1-\mathrm{km}$ site boundary for various materials

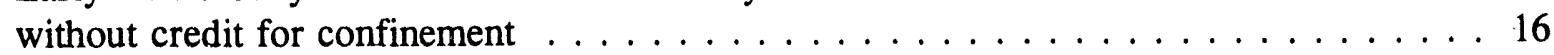

6. Release rates of tungsten and niobium from alloys by both the volatilization and oxide

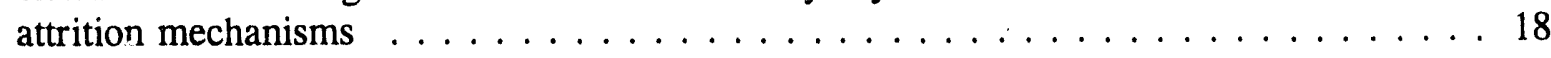

7. ITER toroidal field magnet circuit $\ldots \ldots \ldots \ldots \ldots \ldots \ldots \ldots \ldots$

8. Scrape-off-layer orthogonal mesh used for ITER CDA startup simulation . . . . . . . . 28

9. Scrape-off-layer electron temperature profiles during a startup simulation for an ITER CDA high-recycle divertor case

10. Scrape-off-layer beryllium density profiles $8 \mathrm{~ms}$ into a startup simulation for an ITER CDA high-recycle divertor case

11. Comparison of ATHENA calculations with Forslund dispersed film boiling wall

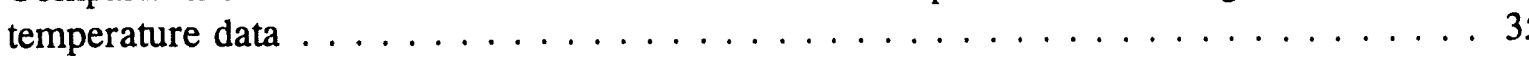




\section{TABLES}

1. Comparison of pressure drops in a uniform magnetic field $\ldots \ldots \ldots \ldots$

2. Proposed actions and alternatives for TFTR D\&D and TPX siting . . . . . . . . . 39 


\section{FUSION SAFETY PROGRAM ANNUAL REPORT FISCAL YEAR 1993}

\section{INTRODUCTION}

Fusion power has the potential to be an important energy source while remaining inherently safe and environmentally attractive. To make this potential a reality requires identifying safety and environmental concerns early and then developing the materials and technology needed to address these concerns.

In 1979, the U.S. Department of Energy (DOE) established the Fusion Safety Program (FSP) to support safety in fusion development. The Idaho National Engineering Laboratory (INEL) has been designated the lead laboratory for fusion safety, and EG\&G Idaho, Inc., is the prime contractor for INEL operations. The main thrusts of the FSP are

- Safety and environmental goals for fusion

- Assessments of safety and environmental issues associated with fusion reactor designs

- Approaches to resolve these issues

- $\quad$ Risk assessment methodologies

- Safety databases

- Computer codes for safety analysis

- Experimental research in fusion-safety related areas.

Realization of fusion's potential will result from advances in plasma physics and technology that enhance safety and environmental protection. Plasma physicists must address issues of plasma disruptions, runaway electrons, emergency plasma shutdown, control of power levels, and reduction of tritium throughput.
Priorities in the technology area to meet the overall goal of attractive fusion power include developing plasma-facing components and breeding blankets that (a) are low in activation products and tritium, and (b) minimize the potential of chemical reactions that would produce explosive quantities of hydrogen or other hazardous substances. Ultimately, low activation materials will be needed for all components and structures exposed to fusion neutrons. The fusion materials community has the challenge to develop such materials. The FSP places a high emphasis on providing technical support and guidance in these critical areas.

International cooperation has become an increasingly important part of the FSP at the INEL. In addition to the cooperation of Japan, the European Community, and the Russian Federation in the International Thermonuclear Experimental Reactor (ITER) design, an agreement for cooperation under the International Energy Agency is now in place. Bilateral cooperation has greatly enhanced fusion safety work. In Fiscal Year 1993, the FSP participated in joint work with the United Kingdom, and we plan to explore additional work with Japan and Italy in the coming year.

Activities performed this fiscal year include experimental tests to develop data for safety analysis, development and maintenance of computer codes and methodology for safety analysis, and studies supporting safety in fusion development. Because safety tests and analyses performed in support of commercial reactors also apply to near-term fusion devices, the FSP was involved in safety support for the Tokamak Physics Experiment (TPX) and the Tokamak Fusion Test Reactor (TFTR) directed by the 
Princeton Plasma Physics Laboratory. Additionally, the FSP participated in the ITER Engineering Design Activity (EDA) in (a) furnishing people to support the ITER Joint Central Team (JCT) at the San Diego, CA and Naka, Japan Joint Work Sites, and (b) leading the U.S. Home Team safety analysis and research participation. Further, we supported the commercial fusion reactor study, ARIES, and its successor study, PULSAR.
The following sections summarize work completed under each of these activities by the INEL and participating organizations, including the Massachusetts Institute of Technology and the University of Wisconsin. The sections, grouped by technical area, present major area accomplishments during the fiscal year and plans for future activities. Appendix A contains abstracts of publications based on work completed. 


\title{
INTERNATIONAL THERMONUCLEAR EXPERIMENTAL REACTOR DESIGN AND REGULATORY SUPPORT
}

\author{
Researchers: D. A. Petti, J. C. Haire, L. C. Cadwallader, \\ D. F. Holland, K. A. McCarthy, and S. J. Piet, INEL
}

The Fusion Safety Program (FSP) leads the U.S. safety and environmental (SAE) effort for the International Thermonuclear Experimental Reactor (ITER). ITER participants are the United States, European Community, Russian Federation, and Japan.

As part of the ITER effort, Drs. D. F. Holland and S. J. Piet were seconded to the ITER Joint Central Team (JCT). Dr. Holland serves as Safety Liaison at the ITER Naka design site in Japan. Dr. Piet is Group Leader for Safety Design and Analysis at the ITER Joint Work Site in San Diego. Upon the secondment of Dr. Piet to the ITER JCT, Dr. D. A. Petti was formally named Task Area Leader for Safety and Standards within the U.S. ITER Home Team.

\section{Major Accomplishments}

ITER Design Support. The goal of our ITER design support is to improve the safety of ITER by identifying key safety issues associated with the evolving ITER Engineering Design Activities (EDA). We also provide recommendations to designers to alleviate or mitigate safety concerns.

Our major work in this area focused on evaluating key safety issues related to coolant selection for ITER. ${ }^{1}$ We reviewed the issues associated with potential coolants, made initial design suggestions to mitigate certain safety concerns, and pointed out serious safety issues associated with each coolant. We felt that these issues detracted from the passive safety potential of ITER and may compromise the ability of ITER to meet its goal of no public evacuation.

We evaluated the following coolants:
Helium

Organic coolant

High-temperature water

Alkali metals ( $\mathrm{Li}, \mathrm{Na}, \mathrm{NaK}$ )

Lead, $\mathrm{Pb}-\mathrm{Bi}$, and $\mathrm{LiPb}$

Gallium

against the following six safety concerns:

- Loss-of-Coolant Accidents (LOCAs) both inside and outside the vacuum vessel. These events may result in (a) pressurization of the vacuum vessel and the radioactivity confinement building due to internal energy of the coolant, and/or (b) pressurization, energy release, radioactivity mobilization, hydrogen production and possible explosion due to coolant chemical reactions with plasmafacing component (PFC) materials, air, water, and concrete.

- $\quad$ Loss-of-Flow Accidents (LOFAs) leading to LOCAs inside the vacuum vessel.

- Management of tritium in coolants to prevent radiation exposure.

- Activation issues including activation of the coolant, transport of activated corrosion products into the coolant, the impact on normal operating releases and accident releases, and maintenance of ex-vessel components.

- Cleanup of surfaces after a LOCA in the vacuum vessel.

- Industrial experience sufficient to ensure safe and reliable operation. 
Because of the number and complexity of the issues involved, we recommend that a systematic integrated approach be used to select (or reject) a coolant for ITER. Our initial evaluation indicated that safety issues exist for each coolant. Many of the modest safety issues can be resolved by design. However, there are serious safety issues associated with the use of certain coolants in ITER. These issues are considered serious enough to potentially threaten regulatory approval of ITER. They may also result in design solutions that will add significant complexity to the system, result in a significant increase in economic cost, or require extensive research and development.

ITER Regulatory Support. ITER is the first fusion machine that will have sufficient decay heat and activation product inventory to pose potential nuclear safety concerns. As a result, nuclear safety and environmental issues will play a much stronger role in the approval process for the design, construction, and operation of ITER in the United States than for previous fusion devices. There are many requirements for regulatory approval of ITER in the United States. As part of our ongoing work in this area, we have summarized these requirements, ${ }^{2,3}$ with the goals of:

- Providing an overview of the regulatory approval process for a Department of Energy (DOE) facility

- Presenting the radiological dose limits used by DOE to protect workers, the public, and the environment from the risks of exposure to radiation

- Highlighting key nuclear safety-related issues that need to be addressed for ITER early in the EDA to help ease regulatory approval.
We also provided the following general guidelines to the ITER JCT concerning the development of a regulatory framework beneficial to ITER and fusion:

- Maintain an approach that focuses on the needs of fusion and ITER.

- Recognize ITER's experimental nature.

- Focus on hazard reduction and passive/ inherently safe design solutions as a means of preventing accidents.

- Implement a graded approach in overall project management such that all requirements are proportionate to the associated risks.

- Integrate the use of risk/benefit and cost/ benefit analyses into the overall graded approach system to help guide development of requirements for regulatory approval.

- In adopting requirements, do not preclude innovative approaches in design and safety.

- Minimize the number of separate documents used to define requirements, thus reducing the potential for contradiction and enhancing the probability of consistent compliance.

\section{Future Activities}

Our future efforts will be to continue improving safety aspects of the ITER design and to begin work with the JCT on their regulatory and safety strategy for ITER by helping them define safety goals and functions and by implementing specific safety features in the ITER EDA design. 


\section{References}

1. D. A. Petti, D. F. Holland, S. J. Piet, K. A. McCarthy, and L. C. Cadwallader, "Key Safety Issues Related to Coolant Selection for ITER," ITER/93/US/EN/SA-2, January 1993.

2. D. A. Petti and J. C. Haire, "Requirements for U.S. Regulatory Approval of the International Thermonuclear Experimental Reactor (ITER) (Draft)," ITER/US/93/EN/SA-7, August 1993.

3. D. A. Petti and J. C. Haire, "Requirements for U.S. Regulatory Approval of the International Thermonuclear Experimental Reactor (ITER), 15th IEEE/NPSS Symposium on Fusion Engineering, October 11-15, 1993, Hyannis, MA. 


\section{TRITIUM SAFETY}

\section{Researchers: T. J. Dolan, J. P. Adams, R. A. Anderl, M. R. Hankins, D. F. Holland, G. R. Longhurst, R. J. Pawelko, and P. D. Ritter, INEL}

Our tritium safety work focuses on attaining ITER goals for keeping soutine and accidental tritium releases within acceptable limits. We are pursuing a broad spectrum of tritium-related studies, including continued development of the INEL tritium laboratory, plasma-driven permeation studies for potential plasma-facing materials (PFM), environmental tritium monitoring around the Tokamak Fusion Test Reactor (TFTR), development of a database for tritium permeation rates and effluents from facilities, maintenance of the TMAP4 code, and participation in the Tritium Plasma Experiment (TPE). Our efforts will ultimately help to limit the ITER tritium hazard by careful design and selection of materials, thus facilitating International Thermonuclear Experimental Reactor (ITER) regulatory compliance and licensing.

\section{Major Accomplishments}

Tritium Research Laboratory. Many improvements have been added to the Tritium Research Laboratory. These improvements include an electrical power upgrade, new demineralized water and drain lines, and an inert-gas supply system for glove boxes. A new tritium monitoring system has been implemented to detect tritium in room air, in the glove-box manifold, and in the hood exhaust. A new gas-analysis system has been developed to measure gas emissions from irradiated specimens.

Glove-box capabilities have been enhanced. We have prepared a glove box for conducting experiments with beryllium, since this element is of prime interest to ITER. A second glove box from Vacuum Atmospheres Corporation with inert gas capability was also installed and operated successfully. This glove-box system will facilitate experiments using environmentally sensitive or hazardous materials in a controlled environment.

\section{Plasma-Driven Implantation and Per-} meation. We have completed studies of hydrogen implantation in and permeation through plasma-sprayed tungsten coatings, sputter-deposited tungsten coatings, and steel substrate. $^{1}$ Extensive characterization analyses of the plasma-sprayed coatings were made using Auger spectrometry and scanning electron microscopy (SEM). Figure 1 shows measured permeation rates as a function of time for representative samples. Specimen thicknesses were $1-\mu \mathrm{m}$ tungsten on $0.5-\mathrm{mm}$ steel for the sputter-deposited specimens, 0.5 -mm steel, and $21-\mu \mathrm{m}$ tungsten on $0.564-\mathrm{mm}$ steel for the plasma-sprayed specimens.

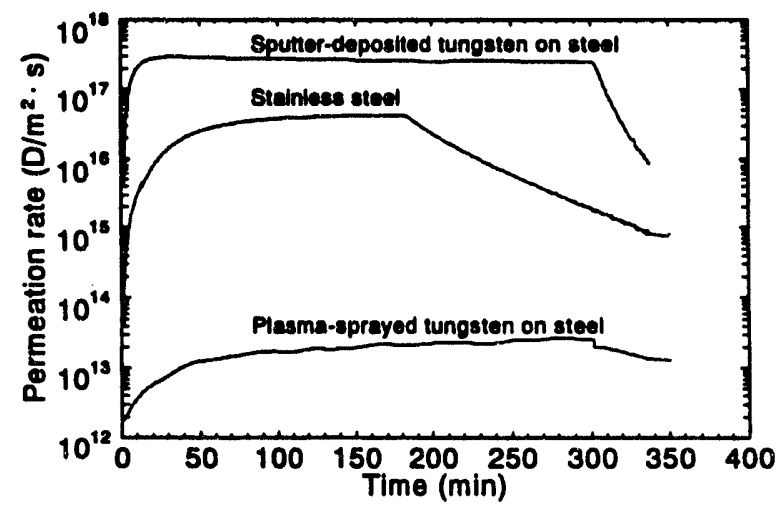

Figure 1. Comparison of measured permeation rates for implanted deuterium in steel and tungsten at $770 \mathrm{~K}$.

The permeation rates through plasmasprayed tungsten coatings on steel specimens were several orders of magnitude lower than the 
rates observed for sputter-deposited tungsten coatings on steel specimens and for pure steel specimens. The plasma-sprayed tungsten coating had an inhomogeneous microstructure. This consisted of splats with columnar solidification, partially melted particles with grain boundaries, and void regions. Its reduced permeation levels are attributed to the complex microstructure and to substantial surfaceconnected porosity, resulting from the deuterium bombardment, as illustrated in Figure 2.

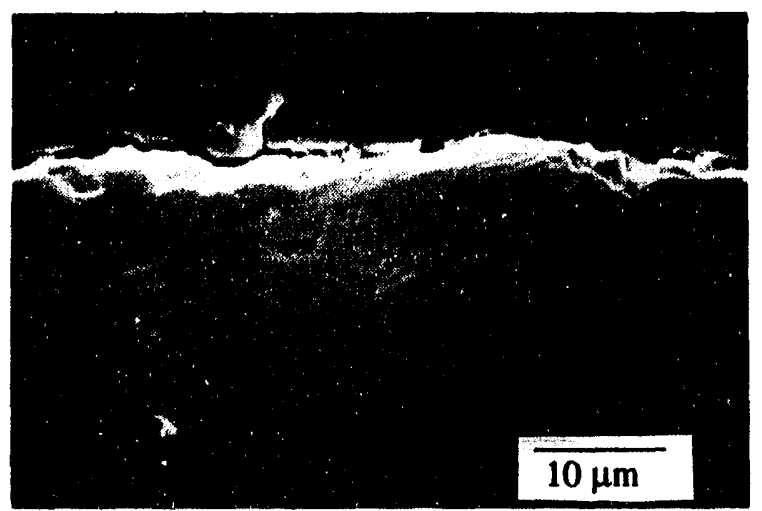

Figure 2. SEM micrograph at $2000 x$ magnification showing the cross section of the plasma-sprayed tungsten coating.

Environmental Monitoring at TFTR. We are providing tritium monitoring support at the Tokamak Fusion Test Reactor (TFTR) site to make time-resolved measurements of tritium in environmental media, in the event of a significant tritium release. ${ }^{2}$ This information can be used to validate models of environmental tritium transport, such as UFOTRI. ${ }^{3}$ We have developed a portable automatic air sampling station that can take 12 samples without human attention. An air pump moves air through both a rotary valve and a series of glass canisters of molecular sieve, as shown in Figure 3.

At designated intervals (such as every 2 hours), the valve is automatically rotated to connect a new glass canister to the pump. Thus, we can measure the tritiated water (HTO) concentration in the air as a function of time

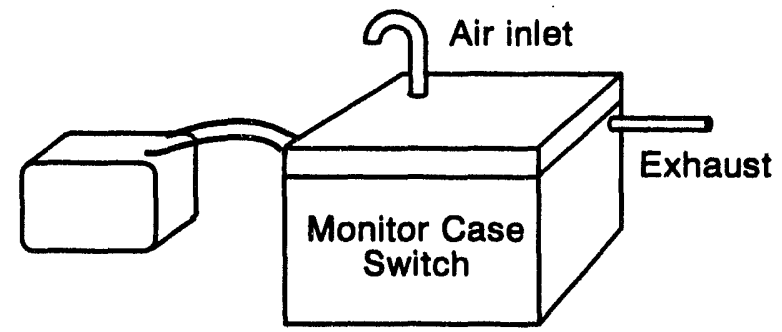

Case Interior

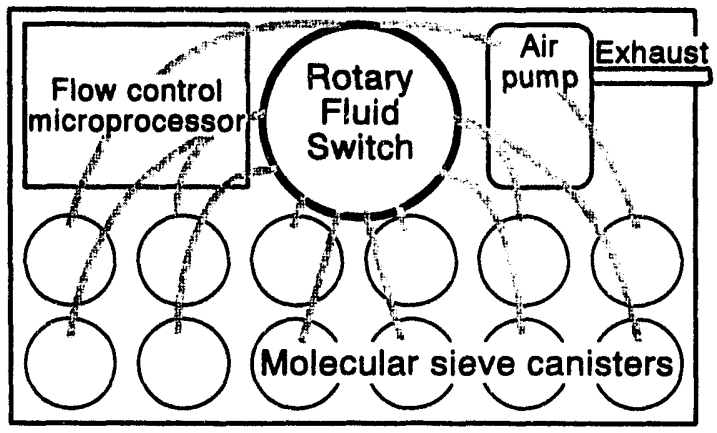

Figure 3. The INEL automatic environmental monitoring station for tritiated water.

without the need for frequent sample replacement by humans. One station became operational in September, and two more are under construction. This sampling station is a unique development by the INEL that may find use at other locations.

We took soil and vegetation samples at TFTR before and after an accidental tritium release of $0.4 \mathrm{TBq}(11 \mathrm{Ci})$ on July 19 and are awaiting their analysis by Princeton. This release was very small, so its value for code validation is uncertain. Rutgers University graduate student Ben Stuart is on call to take data at TFTR if another release occurs.

Tritium Plasma Experiment (TPE). We organized a meeting of TPE participants to discuss the objectives and tasks for TPE. ${ }^{4}$ Other participants are Sandia National Laboratory-Livermore, Los Alamos National Laboratory, and MDC Aerospace. We are contributing to diagnostics planning for this experiment. We drafted a TPE Experimental Program Plan and assisted with design of the 
target holder. Installation of the experiment at the Tritium Systems Test Assembly (TSTA) at the Los Alamos National Laboratory is proceeding smoothly. This includes the design, procurement, and installation of a special glovebox that will facilitate access to the target chamber and be connected to the TSTA Tritiated Waste Treatment system.

Inertial Confinement Fusion. We have participated with Lawrence Livermore National Laboratory and others in the HYLIFE-II inertial confinement fusion conceptual design study ${ }^{5}$ in the areas of tritium management and safety and environment. We completed the report on our HYLIFE-II work ${ }^{6}$ and participated in writing two parts of a forthcoming International Atomic Energy Agency book, Energy from Inertial Fusion. Section 3.6 deals with materials management, especially tritium, and Chapter 6 deals with safety and environment.

\section{Future Activities}

We will measure hydrogen permeation through $\mathrm{Be}$ coatings on $\mathrm{Cu}$ alloy substrates, a material combination of prime interest to ITER. We plan to acquire specimens with $\mathrm{Be}$ on vanadium alloy for future testing. We will finish environmental tritium monitoring at TFTR and explore the possibility of deploying our novel instrumentation at other sites. We will validate the TMAP4 code for use on Macintosh computers. We will participate in the development of diagnostics and target assemblies for the Tritium Plasma Experiment and devise experiments to compare TPE data with permeation data from our Tritium Research Laboratory. We are considering collaborative efforts with other laboratories in areas pertinent to tritium safety. Our work will be focused to provide support for the Safety and Environmental Tasks of the ITER project. 


\section{References}

1. R. A. Anderl, R. J. Pawelko, M. R. Hankins, G. R. Longhurst, and R. A. Neiser, "Hydrogen Permeation Properties of Plasma-Sprayed Tungsten," Proceedings of the 6th International Conference on Fusion Reactor Materials, Stresa, Italy, September 27-October $1,1993$.

2. P. D. Ritter, T. J. Dolan, and G. R. Longhurst, "Tritium Environmental Transport Studies at TFTR," Journal of Fusion Energy, 12, pp. 379-382, 1993.

3. W. Raskob, Description of the New Version 4.0 of the Tritium Model UFOTRI Including User Guide, KFK-5194, August 1993.

4. G. R. Longhurst, "Using the Tritium Plasma Experiment to Evaluate ITER PFC Safety," Journal of Fusion Energy, 12, pp. 349-353, 1993.

5. R. W. Moir et al., HYLIFE-II Progress Report, UCID-21816, December 1991.

6. G. R. Longhurst and T. J. Dolan, HYLIFE-II Tritium Management System, EGG-FSP-9971, June 1993. 


\title{
BERYLLIUM SAFETY
}

\author{
Researchers: G. R. Longhurst, R. A. Anderl, \\ and J. E. O'Brien, INEL
}

Beryllium is contemplated for use in fusion reactors as a plasma-facing material and as a neutron multiplier in breeding blanket applications. There are many aspects of beryllium behavior in a fusion environment that remain to be clarified, such as the response of its mechanical properties to neutron irradiation and the interaction characteristics of tritium implanted from the plasma or bred by transmutations. Some of these issues, which have bearing on safety, are being investigated.

\section{Major Accomplishments}

A key series of experiments in progress for several years investigates the change in mechanical properties of beryllium irradiated in fission reactors. We have previously tested samples of fully dense and partially dense beryllium irradiated in the Advanced Test Reactor (ATR). These samples were irradiated and tested at nominally ambient temperatures. We found that there was approximately a fivefold (a) reduction in ductility and (b) increase in hardness in the irradiated specimens as compared with similar unirradiated ones. ${ }^{1}$

Other specimens have been irradiated as part of the Materials Open Test Assembly (MOTA) in the Fast Flux Test Facility (FFTF) at Hanford, WA. Still others are being irradiated in the Experimental Breeder Reactor II (EBR-II) at the INEL. These specimens have been irradiated at temperatures ranging from 375 to $575^{\circ} \mathrm{C}$. We plan to conduct tests of beryllium mechanical properties at the irradiation temperatures. A quartz-lamp tube furnace has been procured to heat the samples during testing.

The irradiated beryllium samples pose a radiological threat because of the gammaemitting impurity activation and the induced tritium. Also, when the samples undergo brittle fracture, small dust particles are produced that must be considered toxic. Therefore, it is necessary to conduct the tests in a protective enclosure. A Lucite glove box has been constructed that encloses the loading anvils. ${ }^{2}$ It is sealed to the metal structures with silicone and butyl rubber polymers. A key safety question relating to these tests is whether the furnace and heating procedure will threaten the containment in'egrity of the glove box.

To answer that question, we have conducted a series of experiments in which the furnace was installed in a replica of the actual glove box with metal bars simulating the loading anvils on the testing machine. The heating system was then operated under simulated test conditions, and the temperature response of the simulated anvils at their points of closure with the glove box was monitored. Results showed that with water cooling of the anvils, the temperature rise was in good agreement with previous predictions. The anticipated temperature rise in the actual test fixture poses no safety threat.

\section{Future Activities}

We are awaiting the disencapsulation of the samples irradiated in FFTF and the completion of the irradiations in EBR-II. When the samples have been received, we will complete mechanical testing to evaluate the response of their mechanical properties to neutron irradiation. We also plan to conduct tritium retention and release studies on some of the specimens.

Another activity related to beryllium safety will be a survey to determine the state of development of real-time beryllium air concentration monitors. Prototypes have been developed in the U.S. and Russian Federation. 


\section{References}

1. J. M. Beeston, G. R. Longhurst, R. S. Wallace, and S. P. Abeln, "Mechanical Properties of Irradiated Beryllium," Journal of Nuclear Materials, 195, pp. 102-108, 1992.

2. G. R. Longhurst, "Research of Beryllium Safety Issues," Proceedings of the International Workshop on Beryllium for Fusion Applications, Karlsruhe, Germany, October 4-5, 1993 (to be published). 


\section{LOW ACTIVATION MATERIALS}

\section{Researchers: K. A. McCarthy, INEL, G. J. Butterworth, Consultant}

Fusion power has the potential to be a safe and environmentally friendly energy source. Through use of "low activation materials," hazards from accidental release of radioactive materials can be limited, and waste disposal problems can be minimized. The International Thermonuclear Experimental Reactor (ITER) will probably be built from a well-known material such as stainless steel, which is not a low activation material. Thus, parallel to the safety work for materials for ITER, we must look into the safety and environmental aspects of materials that can be used for a DEMO reactor and commercial power reactors. This task supports work in the safety and environmental aspects of low activation materials.

\section{Major Accomplishments}

Our work this year concentrated on the recycle of vanadium alloys. Vanadium alloys show great potential for recycle because most of the transmutation products produced during irradiation are relatively short-lived. Recycling reduces the amount of waste that must be disposed of and saves resources. We concentrated on two aspects of recycling in this study, (1) the effect of the number of usage cycles on the accident dosage resulting from a severe accident, and (2) the recycling options for expired first wall and blanket material.

We calculated mobilization fractions (i.e., fraction of material volatilized due to exposure at high temperatures) for the various elements in the vanadium alloys. These were based on experimental results from the activation products task described elsewhere in this report. Mobilization fractions are useful in comparing materials. In calculating mobilization fractions, we assumed a material thickness of $5 \mathrm{~mm}$, a first wall surface area of $2000 \mathrm{~m}^{2}$, and 1 hour at a given temperature. We used dose information (mSv/Bq) from the PC COSYMA' code for worst-case release conditions (stability class $F$, $1 \mathrm{~m} / \mathrm{s}$ wind speed, ground level release, and $2 \mathrm{~km}$ site boundary) and activation calculations with the code FISPACT $2^{2}$ and the associated library EAF2, together with the mobilization fractions to calculate the offsite early dose as a function of temperature for two vanadium alloys (V-15Cr-5Ti and V-3Ti-1Si). These doses are shown in Figure 4; and for comparison, 316L steei is included.

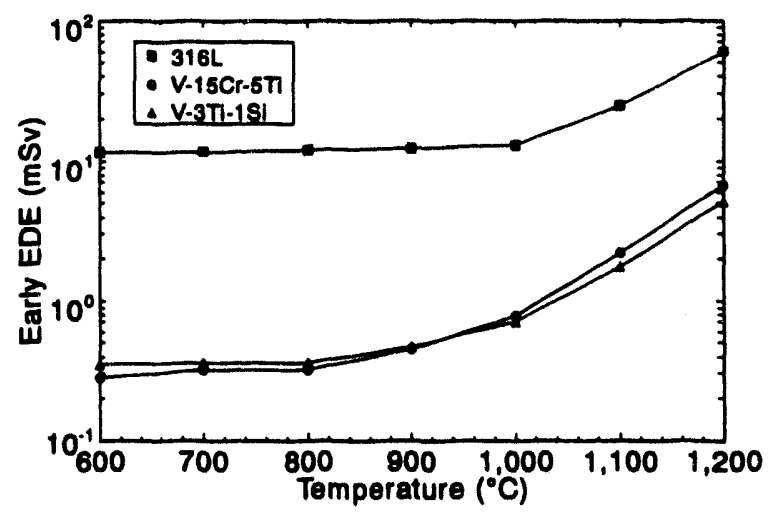

Figure 4. Calculated early doses at 2-km site boundary for vanadium alloys and stainless steel increase with first wall temperature.

We assumed that all material mobilized is released to the environment, with no allowance for radioactivity confinement or plateout. These doses correspond to cycle 1 in the recycling scenario. The dose given is for release from the first wall during 1 hour at that temperature. To calculate the dose from a particular accident, this information would be combined with the accident temperature history. The vanadium alloys are generally about an order of magnitude lower in offsite dose than is the steel. This is due to the low activation nature of the vanadium alloy together with the low mobilization 
fractions of its constituents. The early dose from the two vanadium alloys is very similar. Thus, one is not preferable to the other from a safety point of view.

When mobilization fractions are considered, ${ }^{42} \mathrm{Ar}$ dominates the dose at the lower temperatures while ${ }^{48} \mathrm{Sc}$ dominates at higher temperatures for releases from the $\mathrm{V}-15 \mathrm{Cr}-5 \mathrm{Ti}$ alloy. Since argon is a gas, we assumed that all the argon is released over a typical accident period of 7 days. Inhalation doses for noble gases are generally assumed to be zero. However, an unpublished study on doses from ${ }^{39} \mathrm{Ar}$ and ${ }^{42} \mathrm{Ar}$ indicates that the inhalation dose should be nonzero and may be significant. Thus, the inhalation value used in the dose calculation for ${ }^{42} \mathrm{Ar}$ was large compared with the value that has been traditionally used. ${ }^{3}$ The ${ }^{42} \mathrm{Ar}$ dose issue should be investigated further, since it appears to be an important contributor to dose. Other isotopes contributing more than $5 \%$ to early dose are ${ }^{46} \mathrm{Sc},{ }^{45} \mathrm{Ca}$, and ${ }^{51} \mathrm{Cr}$.

In the V-3Ti-1Si first wall, offsite doses are dominated by ${ }^{24} \mathrm{Na}$ at the lower temperatures and ${ }^{48} \mathrm{Sc}$ at the higher temperatures. We have not tested for the release of sodium from the vanadium alloy; in cases such as this, we use a conservative, temperature-independent mobilization fraction based on the material properties. Other isotopes that contribute more than $5 \%$ to the dose are ${ }^{46} \mathrm{Sc},{ }^{45} \mathrm{Ca}$, and ${ }^{42} \mathrm{Ar}$.

An important question is whether the offsite accident dose increases for an increasing number of cycles through the reactor. Since the dose is dominated by isotopes with relatively short half-lives (with the exception of ${ }^{42} \mathrm{Ar}$ ), these isotopes saturate early in a particular cycle. During the cooling period of 75 years, these isotopes decay so that at the beginning of the cycle, dose levels are practically zero. The argon will be released during heating of the vanadium alloy during reprocessing and therefore not build up in the vanadium alloy with each cycle. Thus, the early dose for each cycle is the same. Chronic doses (50 years of inhalation and resuspension dose, the duration of cloud passage dose, and 50 years of groundshine) are also the same for each cycle.

The waste management options for spent components include either direct disposal in an appropriate (depending on the country) waste repository after a suitable storage period, or recycling to recover the alloy. The recycling option involves remelting the alloy to remove radioactive species and reclaiming the metal for use in new components, with geological disposal of the separated nuclides.

Following its removal from service, material destined for recycling would initially be placed in interim storage to allow decay of the shorter-lived radionuclides. The choice of storage time is determined by two factors: the time at which an external dose rate will permit recycling without excessively stringent radiation protection measures and the desirability of achieving a dose rate in the recycled produce that would allow at least some degree of handson manipulation during its fabrication into new components. The first of these dose rates may be taken to lie in the region of $10 \mathrm{mSv} / \mathrm{h}$ and the second around $10 \mu \mathrm{Sv} / \mathrm{h}$. The deciding factor is the dose rate contributions from particular impurities that would not be removed in the recycling process and, in this context, the most important impurities are cobalt, niobium, molybdenum, and silver. We found a 75-year storage time would be needed to achieve the above dose rate levels in waste consisting of a mixture of $5 \%$ first wall and $95 \%$ blanket material.

Following its removal from service, material destined for recycling would initially be placed in interim storage to allow decay of the shorter-lived radionuclides. Low-activity solid waste from processing of mixed first wallblanket material would amount to about $20 \mathrm{~g}$ of metal per tonne of product and, even when packaged for disposal, its volume would be negligible compared with that of the reclaimed material. The argon released on reprocessing 
could be safely trapped and encapsulated in a stable metal matrix of copper or nickel. Experiments on the immobilization of krypton in a copper matrix ${ }^{4}$ indicate that it should be possible to accommodate the argon from $10^{5}$ tonnes of vanadium alloy in a few kilograms of copper. The copper is even less susceptible to corrosion than the vanadium alloy and the layer containing the argon can, moreover, be covered by any required thickness of inactive metal to minimize the release of the radionuclides until they have decayed to negligible levels. As compared with direct disposal, recycling offers reduced consumption of relatively expensive material, a large reduction in radioactive waste requiring disposal, and a safer means of disposing of argon isotopes.

\section{Future Activities}

Our plans for FY-94 include evaluating the safety of the recycling facilities themselves. The recycling process presents the possibility of the release of radioactive materials. Thus, the benefits of recycling must be viewed with respect to the risk that it may involve. Additionally, we will provide guidarice to a group that will be investigating experimentally the potential for recycling vanadium alloys. 


\section{References}

1. J. A. Jones et al., PC COSYMA: An Accident Consequence Assessment Package for Use on a PC, Commission of the European Communities Report, EUR 14916, 1993.

2. R. A. Forrest and D. A. J. Endacott, FISPACT User's Manual, AERE-M 3654, Atomic Energy Research Establishment, Harwell Laboratory, Oxfordshire, U.K., 1988.

3. Robin Forrest, Dosimetric Data for FISPACT2, AEA FUS 182, Atomic Energy Authority, Abbingdon, Oxfordshire, U.K., 1992.

4. D. S. Whitmell, Immobilization of Krypton-85 in a Metallic Matrix: A Summary, Harwell Laboratory Report, AERE-R 12584, 1987. 


\title{
ACTIVATION PRODUCT CHEMICAL REACTIVITY, VOLATILITY, AND TRANSPORT
}

\author{
Researchers: G. R. Smolik, K. A. McCarthy, D. A. Petti \\ D. L. Hagrman, A. W. Erickson, V. L. Smith-Wackerle \\ and R. S. Wallace, INEL
}

Since activation products formed by 14-MeV neutrons are an accident concern, we examine the behavior of activation products under accident conditions. We study the formation and transport of mobile activation products and chemical reaction rates for potential energy release or hydrogen production. We focus on materials for the divertor, first wall, blanket, and shield, and their behavior at high temperatures during accidents and in oxidizing gases like air and steam.

We have continued developing the database for the volatility of various elements from candidate materials for the first wall and plasma-facing materials for the International Thermonuclear Experimental Reactor (ITER) and commercial fusion reactors. This year, we obtained additional data for a vanadium alloy and for cobalt from steel. This database provides source term information for offsite dose calculations. We continued our investigations into aerosol features and behavior. The purpose of these studies is to provide information on particle sizes, agglomeration, and deposition, thus allowing predictions about aerosol containment. Some of the oxide scales formed by the intrusion of air or steam into the plasma chamber during an accident will probably be removed from the components by spallation. We began to evaluate the potential of this oxide being transported by convective currents and broken into sufficiently small pieces to remain airborne.

\section{Major Accomplishments}

Volatilization Measurements. We measured the volatility of various elements from a $\mathrm{V}-5 \mathrm{Cr}-5 \mathrm{Ti}$ alloy tested in flowing air between 600 and $1200^{\circ} \mathrm{C} .^{1}$ We prepared a vanadium alloy sample including manganese, scandium, and calcium to represent transmutation products. Although there were measurable releases of all elements from this alloy at the highest temperature of $1200^{\circ} \mathrm{C}$, flux determinations for calcium were six to 20 times lower than from our unpublished investigation performed in 1987. Consequently, calculations of offsite dose releases are dominated by ${ }^{24} \mathrm{Na}$ that stems from vanadium alloy impurities, rather than from radioactive calcium isotopes. We have not measured the volatility of sodium because of the difficulties in such a test due to the ubiquitous nature of sodium. In the absence of volatility data, we must use a conservative temperatureindependent mobilization fraction based on material properties. Offsite dose calculations that assume no credit for confinement show that a vanadium alloy design has lower early dose than other candidate materials (see Figure 5).

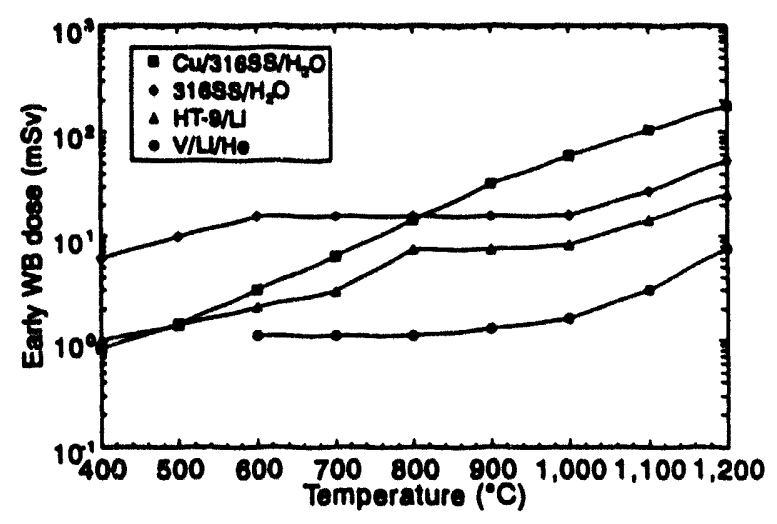

Figure 5. Early whole body dose at $1-\mathrm{km}$ site boundary for various materials without credit for confinement. 
Dose release calculations for steels have shown cobalt to be the domnant activation species. Our previous measurements of cobalt volatility were limited in sensitivity by the analytical method detection limit. We developed improved test procedures using an inductively coupled plasma-mass spectrometer. It is sensitive to a detection limit of $8 \times 10^{-7}$ $\mathrm{g} / \mathrm{m}^{2}-\mathrm{h}$, lower by a factor of 100 than previously measurable. We are currently testing Primary Candidate Alloy (PCA) steel in air. Tests to date show cobalt releases above this detection limit at temperatures of $\geq 1,000^{\circ} \mathrm{C}$. However, calculated dose values will be significantly reduced due to the lower measured cobalt fluxes.

Transport Bohavior Evaluations. We continued our investigations probing the mechanisms of aerosol behavior in fusionrelevant applications. ${ }^{2}$ We tested a tungsten alloy in air and steam environments using a cascade impactor to collect and size particles that left the sample surface. We then characterized particle sizes, morphologies, agglomeration, and chemical make up. Scanning transmission electron microscopy (STEM) showed the primary particles to be typically from 0.03 to $0.15 \mu \mathrm{m}$ in diameter. Calculations based upon aerosol nucleation and transport of tungsten and rhenium oxides in air and steam agreed with the observed primary particle sizes. However, we observed agglomerates up to $25 \mu \mathrm{m}$ in diameter on the cascade impactor substrates. Such agglomeration could not be predicted by the classical models employing Brownian motion, differential gravitational settling, and turbulence. We think that some, as yet uncharacterized, attractive forces are promoting agglomeration and particle-to-particle interactions. This behavior could have significant impact upon aerosol deposition and plate-out in fusion-relevant structures during various potential accident scenarios. It could also influence the amount of activated products released to the environment.
Mechanically Mobilized Aerosols. We initiated investigations to evaluate the potential of aerosol formation from oxide that is spalled, transported by convection currents, and broken into sufficiently small particles to remain airborne..$^{3,4}$ We developed a test cell to measure the tendencies of various oxides to be broken into "micron-size" particles as they are transported in a gas stream. We tested oxides formed from a tungsten alloy, a niobium alloy, and HT9 steel. These preliminary tests have shown that oxide particles of $1 \mu \mathrm{m}$ diameter, or less, are formed when the oxides are transported at $2.5 \mathrm{~m} / \mathrm{s}$. Also, the tendency to form fine particles depends on the oxidation temperature. We have made some preliminary comparisons of elemental releases by oxidation driven volatility and mechanically mobilized pathways (see Figure 6). This figure shows that attrition of oxides can account for significant releases of tungsten and would be the dominant release mechanism for niobium. These preliminary studies indicate that the mechanically mobilized pathway for oxides could be significant and should be considered in future fusion safety evaluations.

\section{Future Activities}

We will continue to focus our experimental efforts on testing of ITER-relevant materials. We will begin data validation in preparation for proviring input for an Environmental Impact Statement (EIS) and a Preliminary Safety Analysis Report (PSAR) for ITER. This will include statistical validation of our data for use in preparing volatility curves. This activity will also help to determine where more tests are needed and to focus on specific elements.

As part of our effort to focus on areas where more data are needed, we will continue our tests of cobalt volatility from PCA steel. We will also carry out more volatility tests on $\mathrm{V}-5 \mathrm{Cr}-5 \mathrm{Ti}$. Additionally, we will begin a volatility modeling task, first focusing on the volatility of sodium in the vanadium alloy. Our 


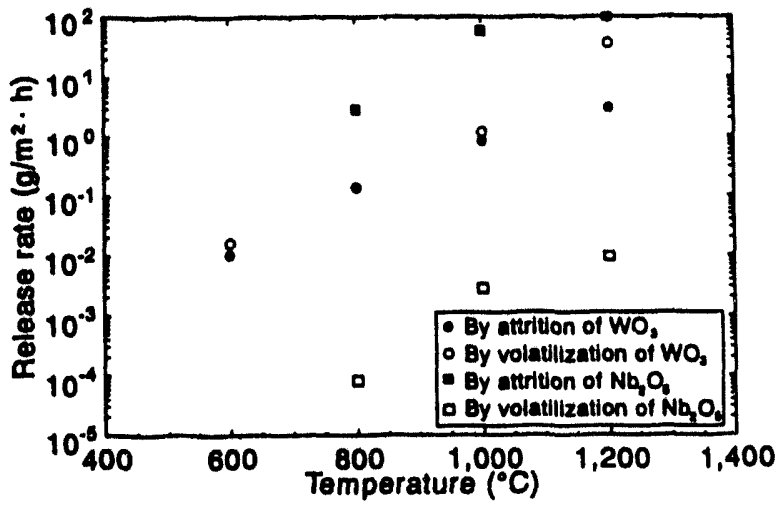

Figure 6. Release rates of tungsten and niobium from alloys by both the volatilization and oxide attrition mechanisms. work in the area of mechanically-mobilized mass will involve additional oxide testing and modeling to check scaling effects between test cell results and a plasma chamber.

We will continue our transport tests, testing vanadium and PCA steel. We are planning to examine the role of aerosol deposition and transport as activated products are released from the first wall and travel through the fusion facility and into the environment. We are currently defining the need for a moderate-scale aerosol transport facility to determine deposition and plate-out in fusion-relevant structures such as the vacuum vessel and cryostat. 


\section{References}

1. K. A. McCarthy and G. R. Smolik, Volatility Measurements from Vanadium Alloys in Air, ITER/US/93/TE/SA-13, September 1993.

2. G. R. Smolik, A. W. Erickson, and D. L. Hagrman, Characterization of Aerosols Released by a Tungsten Alloy, ITER/93/US/TE'SA-6, June 25, 1993.

3. G. R. Smolik, K. A. McCarthy, and V. L. Smith-Wackerle, Oxide Breakup by Convective Currents: Its Role in Activity Release, ITER/US/93/TE/SA-12, September 28, 1993.

4. G. R. Smolik, K. A. McCarthy, and V. L. Smith-Wackerle, "Characterization of Oxide Breakup by Convective Currents," 15th IEEE/NPSS Symposium on Fusion Engineering, Hyannis, MA, October 11-15, 1993. 


\title{
LIQUID METAL CHEMICAL REACTIONS
}

\author{
Researchers: K. A. McCarthy, INEL, L. S. Nelson, J. D. Krueger, \\ J. G. Murphy, G. Vukovic, and M. L. Corradini, UW
}

The liquid metal chemical reactions program has studied hazards associated with liquid lithium and lithium-lead considered for use as tritium-breeding material and with various liquid metals considered for use as a coolant. These hazards include hydrogen production, overpressure, and materials volatilization through chemical heat generation.

This task supports both near-term fusion and commercial reactors. Liquid metals will probably be present in the International Thermonuclear Experimental Reactor (ITER), at least in test modules, with the possibility of use as a coolant or breeder in the blanket/first wall.

\section{Major Accomplishments}

There were two major accomplishments in this task in FY-1993. One was to carry out scoping tests for lithium-organic coolant reactions, and the other was to develop an improved computer model to characterize the fuel/coolant mixing process with hydrogen generation for metal/water interactions.

Molten Lithium-Organic Coolant Interactions. The first wall and blanket in the backup design for ITER has a liquid metal breeder. The design also calls for a watercooled vacuum vessel because of the good shielding characteristics of water. Because of the possibility of a water-lithium reaction, it is desirable to find an alternative to water that shields adequately, but doesn't have the same chemical reactivity hazard. Organic coolants are candidates to take the place of water, and new work this year involved exploratory experiments to determine the severity of a lithium-organic coolant reaction.
We have designed and constructed an apparatus at the University of Wisconsin (UW) to investigate the interactions between drops of molten lithium and organic coolants. To achieve good contact with the denser organic coolant, single drops of molten lithium are released into a stable vortex several centimeters deep produced in the center of the coolant with magnetic stirring. The downward flow that produced the vortex tends to pull the less dense material down into and levitate it below the surface of the denser liquid. The flow of coolant around the vortex should subject the inserted material to forced convection conditions qualitatively similar to those that might accompany a leak in a heat exchanger.

As purified argon flushes through the center and lower sections of the apparatus, a weighed quantity of granular lithium is placed in a preheated crucible via an L-shaped stainless steel sample tube. After an appropriate melting time, the gate is rotated to reltase the molten lithium that falls as a globule into the stirred coolant through a hole centered in the lower stainless steel plate.

In initial tests, we released $0.5-\mathrm{g}$ globules of molten lithium at $200-250^{\circ} \mathrm{C}$ into a vortex formed in magnetically stirred Therminol 66 organic coolant. The coolant was held at room temperature. We usec standard VHS video imaging and a thermocouple in the stirred coolant to provide diagnostics during the interaction. These tests indicated the feasibility of the experimental approach. Subsequently, we developed a test matrix where the organic temperature varied up to $300^{\circ} \mathrm{C}$ and lithium up to $500^{\circ} \mathrm{C}$ with similar masses and experimental procedure. The experiments are currently in progress. Results to date indicate a benign 
reaction when lithium contacts relatively cold $\left(20-100^{\circ} \mathrm{C}\right)$ organic coolant. The lithium exhibits no discernible reaction in the organic. As the organic coolant temperature peaked, with the lithium at its upper limit in temperature, the lithium droplet exhibited a rapid surface blackening, but still it was a very benign event. More tests are under way, and current data are being analyzed.

Model of Fuel/Coolant Mixing Process. With a liquid metal as a likely candidate for coolant and breeder in a commercial reactor, the potential exists, th:ough a heat exchanger leak or a metal spill, for a fuel/coolant interaction (FCI) accident scenario. The FCI can lead to the production of large quantities of steam and hydrogen that can cause overpressurization. The hydrogen generated poses an additional threat from subsequent hydrogen combustion.

We used a simplified hydrogen generation model for FCIs and incorporated it into an existing 1-D hydrodynamic FCI model, TEXAS-II. Modifications were made in the vapor mass balance and particle energy balance to incorporate hydrogen gain and water vapor loss and the energy liberated from the exothermic chemical reaction. The model developed includes the noncondensable (e.g., hydrogen) gas in the system energy and momentum balances (via the mass balance), but it does not include the effect of noncondensable gas in any of the transport rate equations (e.g., condensation rates). This simplified model gives correct physical trends, and sheds some light onto the effects of producing noncondensable gas (hydrogen) in FCI-type scenarios.

The model was applied to molten aluminum-water chemical reactions such as can occur in some fission reactors since data exist on the large-scale phenomena. The UW will incorporate data from lithium lead-water experiments when they become available so the model can be used for fusion reactor calculations.

\section{Future Activities}

If the ITER project continues to show interest in organic coolants, we will carry out further experiments at the University of Wisconsin. These experiments may involve different organic coolants and temperature ranges. We will also perform $100-g$ scale lithium-lead with water chemical reaction kinetics experiments. We will use the results from the experiments in the modified TEXAS-II model to extend the capabilities of the model to fusion-relevant materials. 


\section{MAGNET SAFETY RESEARCH}

\section{J. S. Herring and L. C. Cadwallader, INEL, A. Shajii and J. Freidberg, MIT}

Fusion reactors will require large sets of superconducting magnets, storing over $100 \mathrm{GJ}$ of electrical energy. The safe and reliable operation of these magnets is necessary for near-term experiments and, eventually, for commercial fusion reactors.

Magnet designers need tools to accurately simulate magnet transients, including routine charges and discharges, quench propagation, off-normal and emergency energy dumps, realtime instrumentation, and internal coil shorts and arcs.

\section{Major Accomplishments}

The work on the safety of superconducting magnets focused on two areas during FY-93: (1) the analysis of plausible transients in the International Thermonuclear Experimental Reactor (ITER) toroidal field (TF) magnet set, and (2) the completion of a quench propagation code to determine the energy deposition and hot-spot temperatures resulting from a spreading resistive zone in the winding.

ITER TF Transients. ITER will be the first truly nuclear tokamak with large superconducting magnets. The transient behavior of the TF magnet set, during both routine and off-normal discharges, will be an important factor in assessing potential radionuclide release patterns.

The ITER TF magnets will be among the largest ever made (about 490 tonnes each), and the set will store about $120 \mathrm{GJ}$ in its magnetic field. That stored energy must be safely dissipated when an off-normal condition is detected in the magnet set.

We used the magnet circuit analysis code MSCAP $^{1}$ to analyze the behavior of the pro- posed ITER TF magnet set during expected transients.

The circuit used in this analysis is a reduced model of the TF magnet circuit proposed for the ITER design, ${ }^{2}$ shown in Figure 7, with coil self-inductances and mutual inductances derived from the full 24-coil EDA design. Our purpose in this very preliminary analysis is to screen various components for their importance in magnet transients.

$\mathrm{L} 1, \mathrm{~L} 2$, and $\mathrm{L} 3$ are individual TF coils, and $\mathrm{L} 4$ is a model of the remaining $21 \mathrm{TF}$ coils in the set. R1 through R6 are 0.17- $\mathbf{\Omega}$ dump resistors. $R 7$ and $R 8$ are $3.57 \Omega$ each, modeling the remaining 21 pairs of $0.17-\Omega$ dump resistors. R10 through $R 13$ are $40-\Omega$ resistors connecting the coils to a common groundplane. R20 through R24 are timedependent resistors modeling the behavior of the circuit-breakers across each of the coils. The power supply, V1, is capable of producing $50 \mathrm{~A}$ at $5 \mathrm{kV}$.

Transients Analyzed. The coil L2 and its associated circuit-breaker, R21, dump resistor, $\mathrm{R4}$, and grounding resistor, $\mathrm{R} 12$, are the components of interest in this set of analyses. In principle, these components could be located at any position on the tokamak. Failure of these components must be anticipated sometime during the life of ITER. We have analyzed the following 12 expected transients in the discharge of the TF magnet system:

0 . Base case, $\mathrm{R} 20-\mathrm{R} 24$ open at $\mathrm{t}=2 \mathrm{~s}$.

1. R21 fails to open

2. R21 opens $0.1 \mathrm{~s}$ late

3. R21 opens $1 \mathrm{~s}$ late

4. R21 opens $10 \mathrm{~s}$ late

5. R21 opens at $t=2 \mathrm{~s}$, recloses at $2.1 \mathrm{~s}$ 


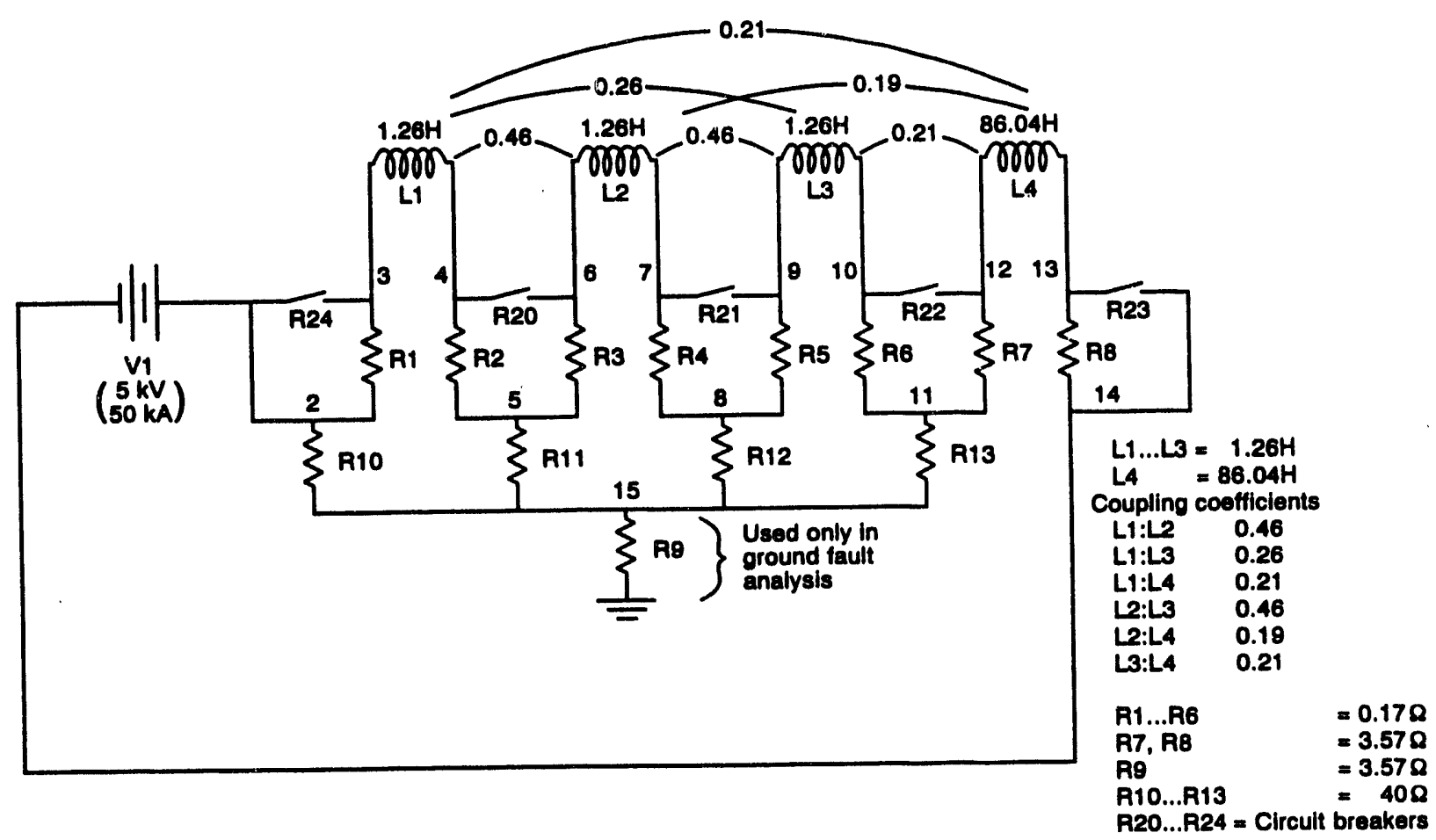

Figure 7. ITER toroidal field magnet circuit.

6. $\mathbf{R} 21$ opens at $t=2 \mathrm{~s}$, recloses at $3 \mathrm{~s}$

7. R21 opens at $t=2 \mathrm{~s}$, recloses at $12 \mathrm{~s}$

8. R4 fails with a high resistance (increases to $1000 \mathrm{ohm}$ in $1 \mathrm{~s}$ )

9. R4 fails short

10. R12 fails open

11. R12 fails short

Results. All of the transients except Case 8 showed a fairly uniform redistribution of the dissipated energy among the other dump circuit components following the failure of a single component. Case 8, the high resistance failure of a dump resistor, caused very high dissipation in the failed resistor and in the adjacent grounding resistors. High dissipation in the grounding resistors would lead to a cascading failure of those resistors. The possibility of such a failure emphasizes the need for several parallel paths in each dump resistor, precluding the possibility of a significant increase in resistance through the failure of a single conductor.
Quench Model Development. At the Massachusetts Institute of Technology (MIT), we have developed a code for modeling quench in cable in conduit conductor (CICC) magnets. ${ }^{3}$ The problem of quench propagation in CICC magnets has been known and qualitatively understood for many years. Several excellent sophisticated numerical codes have been developed to model quench events with sufficient accuracy for engineering design purposes. These codes are fairly general in their engineering and physics content. Consequently, they have the advantage of being able to investigate not only quench propagation, but other phenomena such as startup and stability. However, because of their generality these codes often require long computational times per case (typically several hours of CRAY time for a 3-second quench simulation). Long running times are inconvenient when doing engineering design studies. Faster computation has been the primary motivation for the present work. It has led to a number of advances in 
modeling quench propagation. The main new contributions are summarized below.

A compact model has been developed that focuses solely on the problem of quenching. The model is a simpler form of that used in existing general codes and is obtained by exploiting the high heat transfer between helium and conductor cable and the fact that the flow velocities are highly subsonic.

Because of the simplicity of the model, we have been able to develop a fast, efficient, and robust numerical code. It is fully implicit in time, automatically remeshes the grid to follow the quench front, and requires one to two orders of magnitude less computing time than the existing codes.

The speed and accuracy of the code has been verified by three specific applications. First, a comparison was made with one of the existing general codes on a 2-second simulation of one of the ITER coils. Second, to demonstrate speed, a realistic 50-second quench simulation was performed. Third, a detailed comparison was made with the experimental results of Ando et al. ${ }^{4}$

\section{Future Plans}

During the first months of FY-94, work will conclude on the development and verification of the quench propagation analysis code. As in the past, researchers at MIT will gather information on actual magnet failures and make that information available to the fusion and magnet safety communities.

The magnet safety research task will provide the ITER team with information for the safe design and safety analysis of the magnet sets. We will incorporate this information into a magnet failure database. 


\section{References}

1. H. G. Kraus and J. L. Jones, MSCAP/Mod1 - Magnetic Systems Circuitry Analysis Program, EGG-FSP-9026, March 12, 1990.

2. J. S. Herring, Preliminary Transient Analysis of the ITER Toroidal Field Magnet Set, ITER/US/93/TE/SA-10, p. 4, September 30, 1993.

3. A. Shajii and J. P. Freidberg, Quench in Superconducting Magnets, Part I: Model and Numerical Implementation, PFC/JA-93-10, Plasma Fusion Center, Massachusetts Institute of Technology, July 1993.

4. T. Ando et al., Advances in Cryogenic Engineering, 35, Plenum Press, New York, 1990. 


\section{PLASMA SAFETY}

\section{B. J. Merrill, INEL, and S. C. Jardin, PPPL}

Plasma off-normal events in tokamaks, such as plasma disruptions, plasma overpower transients, and impurity ingress accidents, can produce severe structural damage and potentially mobilize tritium, activated dust, and structural activation products. For example, "hard" plasma disruptions rapidly release the plasma magnetic and thermal energy, creating significant protective tile erosion and induced structural forces. In addition, high loop voltages occur that can generate high-energy runaway electrons. If the generated runaway current is large, these electrons could cause significant first wall and blanket damage when lost from the plasma.

Since the stored energy of tokamak plasmas scales with major radius and plasma current, and since reliable methods for extrapolating disruptive rates to large tokamaks have not been developed, these events are proving to be crucial design and safety issues for next-generation tokamaks. It is therefore important to have some calibrated disruption models to enable meaningful extrapolation to tokamak reactor parameters.

Another plasma safety-related issue is emergency plasma shutdown. Future tokamak divertors and first walls will experience significant heating. A loss-of-coolant accident (LOCA) in these structures will require very rapid plasma shutdown (e.g., less than several seconds for the divertor) to ensure survival of these structures. A shutdown scenario of this timescale that will not induce a 'hard' plasma disruption has not yet been identified. In addition, experiments or detailed models do not exist that would verify the feasibility of presently conceived shutdown scenarios.

With these issues in mind, the focus of this task has been to develop and validate comprehensive models to ensure that proposed reactor designs can safely withstand off-normal plasma events. These models are being added to the Tokamak Simulation Code (TSC), ${ }^{\prime}$ a tokamak free-boundary plasma physics code under development at the Princeton Plasma Physics Laboratory (PPPL). The resulting code is called DSTAR. ${ }^{2}$ In adopting this approach, we deal with plasma off-normal events in a selfconsistent way by accounting for plasma motion, plasma/impurity transport, and induced structural eddy currents.

\section{Major Accomplishments}

We started the development of a scrapeoff-layer (SOL) transport capability for the DSTAR code in FY-1993. ${ }^{3}$ This capability was required to address two areas of safety concern: plasma disruptions and emergency plasma shutdown.

During plasma disruptions, the plasma stored thermal energy is rapidly lost from the plasma and deposited on the divertor. This energy deposition results in significant ablation of the divertor armor material. This ablated material forms a partially ionized vapor cloud above the ablating surface that attenuates the incoming plasma energy. This effect is called vapor shielding. Recent experiments indicate that the effectiveness of this vapor shield to attenuate the plasma energy is highly dependent on the energy of the incident plasma ions and electrons. ${ }^{4}$ To predict the energy of these particles, a SOL transport model is required that accounts for both the plasma and the ablated material.

During the Conceptual Design Activity (CDA) for the International Thermonuclear Experimental Reactor (ITER), ${ }^{5}$ it was estimated that divertor damage would occur following a LOCA if the plasma power was not terminated in less than 10 seconds. $^{6}$ Various shutdown 
schemes were proposed, two of which are outgassing from the divertor armor material (a passive system) and gaseous impurity injection (an active system). To determine the effectiveness of these schemes, a SOL transport model is required that accounts for the hydrogen plasma and the injected plasma impurities.

The transport equations of our model are similar to those used by most SOL transport modelers. ${ }^{7,8,9}$ We have derived these equations from Braginskii's plasma transport equations. ${ }^{10}$ These equations include conservation of density, momentum, and energy.

\section{Particle Density Conservation.}

$$
\frac{\partial}{\partial t} n_{a}+\nabla \cdot\left[n_{a} \bar{v}_{a}\right]=S_{n}^{a}
$$

where

$$
\begin{aligned}
& \mathrm{n}_{2}=\text { plasma species "a" density }\left(\mathrm{m}^{-3}\right) \\
& \vec{v}_{\mathrm{a}}=\text { velocity of plasma specie " } \mathrm{a} \text { " }(\mathrm{m} / \mathrm{s})
\end{aligned}
$$

This equation is solved for both the hydrogen and impurity plasma species, for both the neutral and ionized charge states. The source term of this equation includes charge exchange ionization, electron impact ionization, radiative electron recombination, divertor plate recycling, divertor plate sputtering, gas puffing, and vacuum system pumping.

Momentum Conservation.

$$
\begin{gathered}
m_{a} n_{a}\left(\frac{\partial}{\partial t}+\overrightarrow{\mathrm{v}}_{\mathrm{a}} \cdot \nabla\right) \overrightarrow{\mathrm{v}}_{\mathrm{a}}=-\nabla p_{a}- \\
\frac{Z_{a} n_{a}}{n_{e}} \nabla p_{e}+Z_{a} n_{a}\left[\frac{Z_{a}}{Z_{e f f}}-1\right] \times \\
\left(C_{e} \nabla_{1} T_{e}+c_{i} \nabla_{1} T_{i}\right) \\
+\sum_{b=1}^{N} \vec{F}_{a b}+\vec{S}_{m}^{a}
\end{gathered}
$$

where

$$
\begin{aligned}
& \mathrm{m}_{\mathrm{a}}=\text { mass of plasma specie "a" (kg) } \\
& p_{a, c}=\text { plasma species " } a \text { " and electron } \\
& \text { pressures }(\mathrm{Pa}) \\
& Z_{a}=\text { charge of plasma specie " } a \text { " } \\
& Z_{\text {eff }}=\text { effective plasma charge } \\
& C_{0, i}=\text { coefficients of the thermal electric }
\end{aligned}
$$

The frictional force term, (e.g., $\sum_{b=1}^{N} \vec{F}_{a b}$ ), accounts for the coulomb interactions between the hydrogen and impurity ions.

Energy Conservation. Conservation of energy equations are solved for both the electrons and ions of the SOL plasma. For the electrons, this equation is

$$
\begin{aligned}
& \frac{3}{2} \frac{\partial}{\partial t} n_{e} T_{e}+ \\
& \nabla \cdot\left[\frac{5}{2} n_{e} T_{e} \bar{v}_{e}-\kappa_{i}^{e} \nabla_{1} T_{e}-\kappa_{\perp}^{e} \nabla_{\perp} T_{e}\right] \\
& \quad=v_{e} \cdot \nabla n_{e} T_{e}-\mathrm{K}\left(T_{e}-T_{i}\right)+S_{E}^{e}
\end{aligned}
$$

and for the ions

$$
\begin{aligned}
& \frac{3}{2} \frac{\partial}{\partial t} \sum_{a=1}^{N} n_{a} T_{i}+ \\
& \nabla \cdot\left(\frac{5}{2} \sum_{a=1}^{N} n_{a} T_{i} \overrightarrow{\mathrm{v}}_{\mathrm{a}}-\kappa_{1}^{i} \nabla_{1} T_{i}-\kappa_{\perp}^{i} \nabla_{\perp} T_{i}\right) \\
& \quad=\sum_{a=1}^{N} \overrightarrow{\mathrm{v}}_{\mathrm{a}} \cdot \nabla n_{a} T_{i}+\mathrm{K}\left(T_{e}-T_{i}\right)+S_{E}^{i}
\end{aligned}
$$

where

$$
\begin{aligned}
& \mathrm{T}_{\mathrm{e}}=\text { electron temperature }(\mathrm{eV}) \\
& \mathrm{T}_{\mathrm{i}}=\text { ion temperature }(\mathrm{eV}) \\
& \mathrm{v}_{\mathrm{e}}=\text { electron velocity }(\mathrm{m} / \mathrm{s}) \\
& \kappa_{1}=\begin{array}{l}
\text { parallel thermal conductivity } \\
\left(\mathrm{m}^{-2}-\mathrm{s}^{-1}\right)
\end{array} \\
& \kappa_{\perp}=\begin{array}{l}
\text { perpe ndicular the r ma l } \\
\text { conductivity }\left(\mathrm{m}^{-2}-\mathrm{s}^{-1}\right)
\end{array} \\
& \mathrm{K}=\begin{array}{l}
\text { ion/electron thermal equipartition } \\
\text { constant }\left(\mathrm{m}^{-3}-\mathrm{s}^{-1}\right) .
\end{array}
\end{aligned}
$$

These conservation equations are solved on an orthogonal magnetic coordinate system 
$(\psi, \theta, \phi)$, where $\psi$ is the plasma poloidal flux (Wb), $\theta$ is the poloidal angle, and $\phi$ is the toroidal angle, along which angle we assume symmetry.

We have applied our model to the ITER CDA design. For this analysis, we used the computational mesh shown in Figure 8. This mesh is essentially a one-dimensional mesh with three radial zones. The first and third zones are boundary zones for this application. The plasma edge temperature was arbitrarily increased from 13 to $160 \mathrm{eV}$ in $0.25 \mathrm{~ms}$, and the electron edge density was held constant at 2 $\times 10^{20} \mathrm{~m}^{-3}$. The radial diffusion coefficient was taken as $1.0 \mathrm{~m}^{2} / \mathrm{s}$, and the ion and electron perpendicular thermal conductivities as 0.2 and $4.0 \mathrm{~m}^{-2}-\mathrm{s}^{-1}$, respectively. The vacuum system pumping speed was set at $1000 \mathrm{~m}^{3} / \mathrm{s}$. Finally, coefficients for divertor plate recycle, and physical and self-sputtering were taken as 1.0 , 0.01 , and 0.05 , respectively. These values are typical of those of the CDA design."
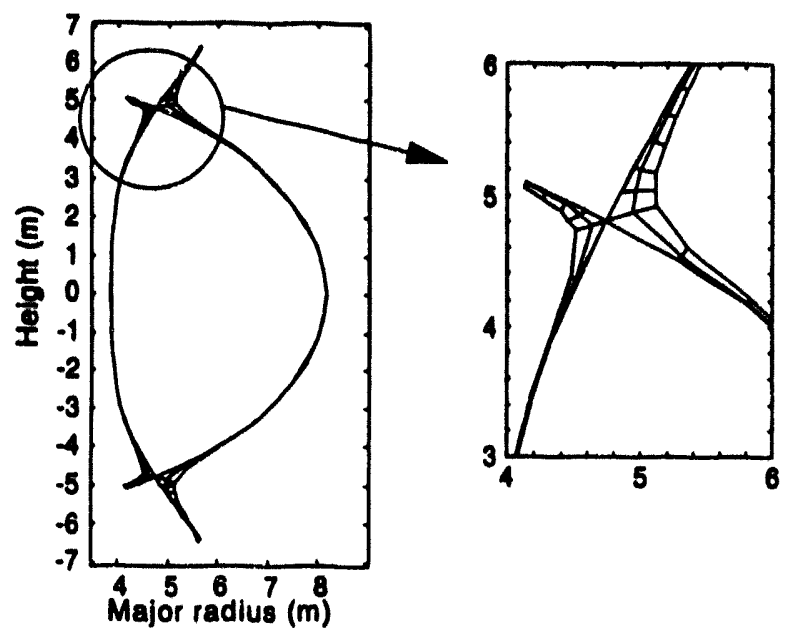

Figure 8. Scrape-off-layer orthogonal mesh used for ITER CDA startup simulation.

Figure 9 contains the poloidal electron temperature profile for the outer SOL as it develops in time. The mid-plane temperature at steady conditions is $157 \mathrm{eV}$, and the temperature near the divertor plate is $55 \mathrm{eV}$. The ion temperature at these same locations is $154 \mathrm{eV}$
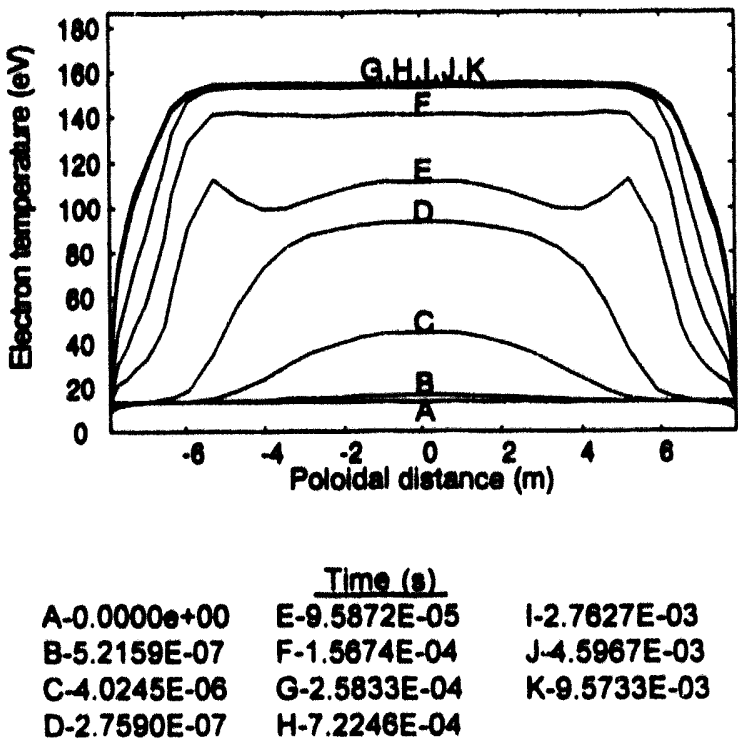

Figure 9. Scrape-off-layer electron temperature profiles during a startup simulation for an ITER CDA high-recycle divertor case.

and $34 \mathrm{eV}$, respectively. The predicted power crossing the separatrix for this case is $60 \mathrm{MW}$.

The beryllium density profiles for the outer SOL at $0.25 \mathrm{~ms}$ are shown in Figure 10. The density of $\mathrm{Be}^{+4}$ peaks $0.25 \mathrm{~m}$ from the divertor plate at a value of about $3 \times 10^{18} \mathrm{~m}^{-3}$. This density drops off three orders in magnitude near the mid-plane of the plasma. The shape of this profile is primarily determined by a balance between the frictional drag exerted on the beryllium by the hydrogen ions flowing toward the divertor and the inertial forces exerted by the beryllium.

\section{Future Activities}

Development of the DSTAR impurity SOL transport model will continue in the next fiscal year. This model will be applied to ITER to determine if passive plasma shutdown scenarios by impurity gas injection are feasible.

In addition, DSTAR validation studies will continue with comparisons being made between predictions and tokamak disruption data. 


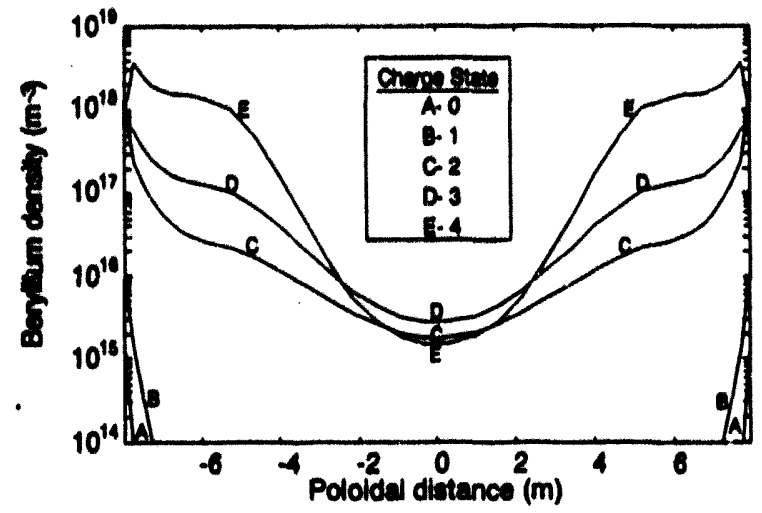

Figure 10. Scrape-off-layer beryllium density profiles $8 \mathrm{~ms}$ into a startup simulation for an ITER CDA high-recycle divertor case. 


\section{References}

1. S. C. Jardin, N. Pomphrey, and J. Delucia, "Dynamic Modeling of Transport and Positional Control of Tokamaks," Journal of Computational Physics, 66, p. 481, 1986.

2. B. J. Merrill, S. C. Jardin, "DSTAR: A Comprehensive Tokamak Resistive Disruption Model for Vacuum Vessel Components," Fusion Engineering and Design, 5, pp. 235-249, 1987.

3. B. J. Merrill, S. C. Jardin, A Description and Application of a Scrape-off-Layer Model for the DSTAR Code, ITER/US/93/TE/SA-14, U.S. ITER Home Team, Oak Ridge, TN, September 1993.

4. A. Hassanien, Proceedings of U.S.-Japan Workshop Q-142, SAND92-0222, Sandia National Laboratory Report, pp. 3-27, November 1991.

5. ITER Physics, IAEA ITER Documentation Series, No. 21, International Atomic Energy Agency, Vienna, p. 105, 1991.

6. ITER Plasma-Facing Components, IAEA ITER Documentation Series, No. 30, International Atomic Energy Agency, 1990.

7. B. J. Braams, A Multi-fluid Code for Simulation of the Edge Plasma in Tokamaks, EURFU/XII-80/87/68, Commission of the European Communities NET Report, Brussels, January 1987.

8. M. Keilhacker, R. Simonini, A. Taroni, M. L. Watkins, "Scrape-off Layer Model for the Study of Impurity Retention in the Pumped Divertor Planned for JET, "Nuclear Fusion, 31, No. 3, 1991.

9. D. A. Knoll, P. R. McHugh, "NEWEDGE: a 2D Fully Implicit Edge Plasma Fluid Code for Advanced Physics and Complex Geometries," Journal of Nuclear Materials, 196-198, pp. 352-356, 1992.

10. S. 1. Braginskii, "Transport Process in a Plasma," Reviews of Plasma Physics, Vol. 1, M. A. Leontovich (ed.), Consultants Bureau, New York, pp. 214-219, 1965. 


\section{Researchers: L. C. Cadwallader, M. L. Abbott, A. S. Rood, and P. D. Ritter, INEL \\ T. D. Marshall, Rennselaer Polytechnic Institute S. L. Harms, University of Callfornia, Santa Barbara}

Risk assessment has beell used successfully in large U.S. Department of Energy (DOE) design projects to incorporate reliability and safety into the design activity.' This risk-based approach can also be used in the International Thermonuclear Experimental Reactor (ITER) design activity. Also, DOE directs probabilistic approaches for regulatory safety analysis of its nuclear facilities. ${ }^{2,3}$ Two important requirements for risk assessment, either for risk-based design or regulatory reports, are a component failure rate database for quantification of the event sequence frequencies, and a radiological dose code for fusion event consequence analysis. We report here on our activities in both the fusion-component failure data collection and fusion-relevant dose code areas.

\section{Major Accomplishments}

Component Fallure Rates. We calculated failure rates based on operating experiences from the Tritium Systems Test Assembly (TSTA) at Los Alamos National Laboratory, in a continuing task to analyze TSTA systems. In cooperation with personnel from TSTA, we examined the Experimental Tritium Cleanup (ETC) system, which is a room air detritiation system. ${ }^{4}$ The ETC system has only operated for a few hundred hours for testing purposes, so the calculated failure rates did not compare well with other published data. ${ }^{3}$ One notable feature from the analysis was a decrease in component failure rates by factors varying from 8 to more than 20 between the early system testing and useful life phases of the ETC system.

In another task, we worked to compile failure mechanisms and operating experience data for a variety of potential ITER in-vessel cooling tubes. The materials considered were inconel, steel, copper, beryllium, titanium (to infer values for vanadium), and zirconium (to infer values for niobium). Titanium tube leakage and rupture failure rates, including multiplicative factors to account for harsh fusion environmental conditions, were the lowest values. Therefore, we concluded that titanium tubing would be the best choice from a coolant leak perspective. ${ }^{6}$ This work will be published in FY-94.?

Dose Consequence Computer Codes. Cooperative work with Sandia National Laboratory (SNLA) on the MELCOR Accident Consequence Code System (MACCS) ${ }^{8}$ has proceeded well. Dr. L. Miller of SNLA conducted a U.S.-based peer review of the new MACCS version in February and March. Results of this peer review have been incorporated into MACCS. The code now can handle more than 500 radionuclides (for both fusion and fission) and uses the INEL-developed food chain model COMIDA.9,10 The new version of MACCS should be released for general use in 1994.

We worked with MACCS to calculate radiological doses for each MACCS radionuclide (in sieverts per terabecquerel released). We considered three accident cases of ITER interest. The first case was a groundlevel release with class $F$ atmospheric stability. The second case was a ground-level release with $1.3 \mathrm{~mm} /$ hour rainfall and class $E$ atmospheric stability. The final case was a $100-\mathrm{m}$ release height (stack release) with class $D$ atmospheric stability. These three cases are quite versatile; they can be scaled for a variety of atmospheric 
stability classes, wind speeds, and downwind distances $(100 \mathrm{~m}$ to $80 \mathrm{~km})$. The results can be accessed through a spreadsheet macro developed for convenient calculation of such parameters and combination of radionuclides as the user desires." These parameter studies will be quite useful to ITER environmental and safety work as the design evolves.

\section{Future Activities}

We plan to continue collecting fusion component failure rate data to support compilation of a scoping data handbook for the ITER design. Future data collection will focus on large cryostats, cryostat penetrations, and in-vessel components to support ITER studies. We will continue to work with the MACCS computer code to better characterize the effects of a simultaneous liquid nitrogen and radionuclide release. We expect that liquid nitrogen will initially exhibit negative buoyancy, but the extent of this effect has not been quantified. We will also examine normal effluent releases using the same parameterization approach as the already-examined accident releases. We will use the validated and verified Radiological Safety Analysis Computer (RSAC) code $^{12}$ to calculate normal effluent doses. This dose code work also supports ITER safety and environmental studies. 


\section{References}

1. R. M. Harrington, "PRA in the Design of the Advanced Neutron Source," DOE Risk Management Quarterly, 1, October 1993.

2. DOE Order 5480.23, Nuclear Safety Analysis Reports, April 30, 1992.

3. DOE Standard 1027-92, Hazard Categorization and Accident Analysis Techniques for Compliance with DOE Order 5480.23, Nuclear Safety Analysis Reports, December 1992.

4. L. C. Cadwallader and G. L. Taylor, Experimental Tritium Cleanup System Availability Analysis from 1984 to 1992, EGG-FSP-10603, May 1993.

5. L. C. Cadwallader and G. L. Taylor, "Failure Rate Data for Glove-Box Components and Cleanup Systems at the Tritium Systems Test Assembly," Journal of Fusion Energy, 12, pp. 281-285, 1993.

6. T. D. Marshall and L. C. Cadwallader, "Recommended In-Vessel Tubing Failure Rate Values for the International Thermonuclear Experimental Reactor," 15th IEEE Symposium on Fusion Engineering, Hyannis, MA, October 11-14, 1993.

7. T. D. Marshall and L. C. Cadwallader, In-Vessel ITER Tubing Failure Rates for Selected Materials and Coolants, EGG-FSP-10928 (to be published).

8. D. I. Chanin et al., MELCOR Accident Consequence Code System (MACCS) User's Guide, NUREG/CR-4691, SAND86-1562, February 1990.

9. M. L. Abbott and A. S. Rood, "COMIDA: A Radionuclide Food-Chain Model for Acute Fallout Deposition," accepted for publication in Health Physics on May 7, 1993.

10. M. L. Abbott and A. S. Rood, COMIDA: A Radionuclide Food-Chain Model for Acute Fallout Deposition, EGG-GEO-10367, November 1993.

11. M. L. Abbott, S. L. Harms, and A. S. Rood, Dose Calculations for Accidental Airborne Releases of ITER Activation Products (Draft), EGG-EEL-10994, September 1993.

12. D. R. Wenzel, Radiological Safety Analysis Computer Program (RSAC-5) User's Manual, WINCO-1123, Westinghouse Idaho Nuclear Company, October 1993. 


\title{
ATHENA DEVELOPMENT
}

\author{
Researchers: K. E. Carlson, J. E. Tolli, and B. J. Merrill, INEL
}

Fusion experiments, and eventually fusion reactors, will require several interacting coolant systems to remove heat from the first wall, blanket, limiter or divertor, and cryogenic superconducting magnets. Different cooling fluids will be used in each of the systems. These separate systems will be interconnected by heat exchangers and can be affected by plasma or magnetic field configuration variations that cause the power being delivered to these cooling systems to change.

To understand and analyze the interactions among these cooling systems, the INEL is developing a transient analysis code called ATHENA $^{1}$ to simulate both routine and accident conditions. This code will eventually provide an advanced best-estimate predictive capability for use in a wide spectrum of fusion reactor transient applications.

ATHENA is based on a nonequilibrium model of the two-phase fluid conservation equations, which are solved by a fast numerical scheme to permit economical calculations for cooling system transients. The objective of the ATHENA development effort has been to produce a code that includes important first-order effects necessary for accurate prediction of system transients but that is sufficiently simple and cost effective that parametric or sensitivity studies are possible.

The code includes many generic component models from which general systems can be modeled. The component models include pumps, valves, pipes, heat structures, reactor point kinetics, electric heaters, jet pumps, turbines, separators, and control system components. In addition, special process models are included for effects such as form losses, flow at abrupt area changes, branches, choked flow, magnetohydrodynamic (MHD) effects, solute tracking and noncondensable gases.
The ATHENA code is based on the RELAP5/MOD3 code $^{2}$ and is being developed by modifying RELAP5 to include a range of fluids and new constitutive models. By adopting this approach, ATHENA benefits from extensive experience in modeling two-phase processes of Light Water Reactor (LWR) systems and from the validation experience with experimental fission reactor data. Additional experience has been gained through use of ATHENA by many research and development institutions in the U.S. abroad.

\section{Major Accomplishments}

We completed two model development tasks this year. The first improved the accuracy of ATHENA's dispersed film boiling heat transfer prediction for liquid nitrogen $\left(\mathrm{LN}_{2}\right){ }^{3}$ Dispersed film boiling is a heat transfer regime that occurs after the surface heat flux exceeds that which can be removed by liquid boiling; and the coolant vaporizes to the point where it exists as vapor containing dispersed liquid droplets. This improvement was obtained by implementing a heat transfer model proposed by R. P. Forslund ${ }^{4}$ for this heat transfer regime in ATHENA. Forslund's model includes the following correlation for heat transfer between the wall and the droplets near the wall:

$$
\begin{aligned}
h=K\left(\frac{\pi}{4}\right) & {\left[\frac{6 G(1-X)}{\left(\pi \rho_{l} V_{l}\right)}\right]^{\frac{2}{3}} \times } \\
& {\left[\frac{k^{3} H_{f g}^{*} g \rho_{v} \rho_{l}}{D\left(T_{W}-T_{s a l}\right)} \mu\left(\frac{\pi}{6}\right)^{\frac{1}{3}}\right]^{\frac{1}{4}} }
\end{aligned}
$$

where

$K=0.2$, as determined by Forslund,

$G \quad=$ mass flux $\left(\mathrm{kg} / \mathrm{m}^{2}-\mathrm{s}\right)$

$\boldsymbol{X}=$ quality 


$$
\begin{array}{ll}
D & =\text { droplet diameter }(\mathrm{m}) \\
\rho_{v}, \rho_{l} & =\text { vapor and liquid densities }\left(\mathrm{kg} / \mathrm{m}^{3}\right) \\
V_{v}, V_{l} & =\text { vapor and liquid velocities }(\mathrm{m} / \mathrm{s}) \\
k & =\text { thermal conductivity }(\mathrm{W} / \mathrm{m}-\mathrm{K}) \\
g & =\text { gravitational constant } \\
T_{w} & =\text { wall temperature }(\mathrm{K}) \\
T_{s a t} & =\text { droplet saturation temperature }(\mathrm{K}) \\
\mu & =\text { viscosity }(\mathrm{kg} / \mathrm{m}-\mathrm{s}) \\
H_{f g} & =H_{f g} l 1+0.35 C_{p}\left(T_{w}-T_{s a t}\right) / H_{f g} J^{3}
\end{array}
$$

where

$$
\begin{aligned}
H_{f g} & =\text { latent heat of vaporization }(\mathrm{J} / \mathrm{kg}) \\
C_{p} & =\text { heat capacity }(\mathrm{J} / \mathrm{kg}-\mathrm{K}) .
\end{aligned}
$$

We have developed correlations for droplet diameter as a function of relative velocity (e.g., $V_{v}-V_{\nu}$ and local wall heat flux based on droplet size data given by Forslund. Forslund's experiment introduced slightly subcooled LN2 into a 2.4-m stainless steel pipe with an inside diameter of $9.2 \mathrm{~mm}$. The test section was electrically heated to produce heat fluxes up to $8,800 \mathrm{~W} / \mathrm{m}^{2}$ and was instrumented axially with thermocouples every $0.1 \mathrm{~m}$.

Figure 11 contains a comparison of measured and predicted wall temperatures versus axial location for three different surface heat fluxes in Forslund's experiment. Adequate agreement was obtained with this new heat transfer model.

The second model development task was to improve ATHENA's magnetohydrodynamic (MHD) pressure drop model. ${ }^{5}$ The predicted pressure drop for liquid metals flowing through a time-independent magnetic field is now determined from

$$
\frac{\partial P}{\partial x}=\left[\frac{1}{1-M}-\frac{\phi}{1+\phi+\epsilon}\right] f_{\text {config }} \sigma_{f} \nu B^{2}
$$

where

$$
\begin{aligned}
& P=\text { fluid pressure }(\mathrm{Pa}) \\
& \mathrm{X}=\text { channel length }(\mathrm{m})
\end{aligned}
$$

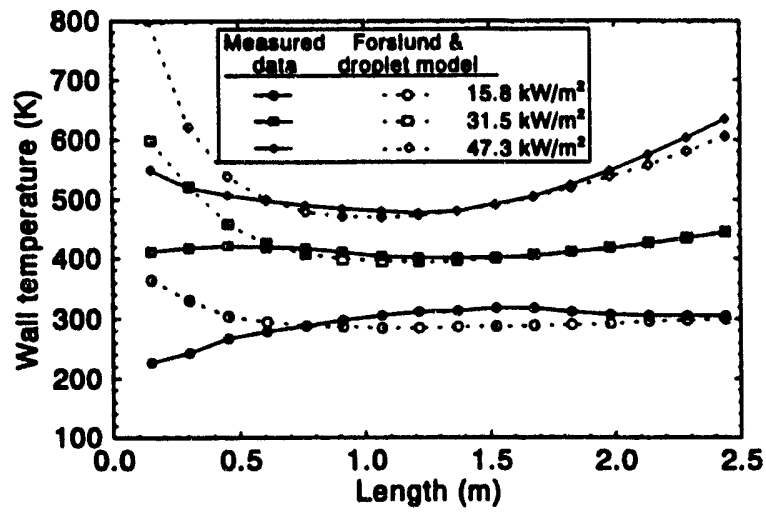

Figure 11. Comparison of ATHENA calculations with Forslund dispersed film boiling wall temperature data.

$$
\begin{aligned}
M & =\text { Hartmann number }=B a \sqrt{\frac{\sigma_{f}}{\mu_{f}}} \\
\phi & =\text { wall conductance ratio }=\frac{\sigma_{w} t_{w}}{\sigma_{f} a} \\
\sigma & =\text { electric conductivity }(1 / \Omega-m) \\
\nu & =\text { velocity }(\mathrm{m} / \mathrm{s}) \\
B & =\text { magnetic field strength (tesla) }
\end{aligned}
$$

where

$$
\begin{aligned}
& t_{w}=\text { wall thickness (m) } \\
& a=\text { duct half width (m). }
\end{aligned}
$$

The terms $f_{\text {confis }}$ and $\epsilon$ account for spatially varying magnetic fields and noncircular ducts, respectively. These quantities were determined by running a two-dimensional MHD computer code for a variety of MHD conditions to produce ATHENA interpolation tables.

We have compared the predictions from this MHD pressure drop model to pressure drop data from the ALEX facility. These data were for circular and square ducts in a spatially constant magnetic field. The results are contained in Table 1. This table shows that 
Table 1. Comparison of pressure drops in a uniform magnetic field.

\begin{tabular}{cccccc}
\hline $\begin{array}{c}\text { Duct } \\
\text { Type }\end{array}$ & $\begin{array}{c}\mathrm{B} \\
(\text { Tesla })\end{array}$ & $\begin{array}{c}\text { Velocity } \\
(\mathrm{m} / \mathrm{s})\end{array}$ & $\begin{array}{c}\Delta \mathrm{P}_{\text {ALEX }} \\
(\mathrm{Pa})\end{array}$ & $\begin{array}{c}\Delta \mathrm{P}_{\text {ATHENA }} \\
(\mathrm{Pa})\end{array}$ & $\begin{array}{c}\text { Deviation } \\
(\%)\end{array}$ \\
\hline Circular & 2.1 & 0.285 & $5.9 \times 10^{4}$ & $6.25 \times 10^{4}$ & 5.85 \\
Circular & 1.1 & 0.285 & $1.8 \times 10^{4}$ & $1.72 \times 10^{3}$ & -4.22 \\
Circular & 1.1 & 0.077 & $4.3 \times 10^{3}$ & $4.66 \times 10^{3}$ & 8.30 \\
Square & 2.1 & 0.0038 & $8.0 \times 10^{2}$ & $6.84 \times 10^{2}$ & -14.5 \\
Square & 1.1 & 0.225 & $9.4 \times 10^{3}$ & $9.46 \times 10^{3}$ & 0.61 \\
\hline
\end{tabular}

the agreement between ATHENA predictions and ALEX data is good. Deviations are larger at low flows, as would be expected, since ATHENA's pressure drop formulation is applicable for fully developed turbulent flow.

\section{Future Activities}

During the upcoming fiscal year, we will add to the ATHENA code a liquid metal heat transfer model for flow through magnetic fields. We will be contacting ATHENA users to inform them that a new version is ready for release.

The goal of future ATHENA-user support will be to assist in the widest possible use of ATHENA by the ITER community. Design and safety analysis support will also be provided to the ITER design study. 


\section{References}

1. K. E. Carlson, P. A. Roth, and V. H. Ransom, ATHENA Code Manual, Volume 1 and 2, EGG-RTH-7397, September 1986.

2. C. M. Allison et al., RELAP5/MOD3 Code Manual, Volumes 1, 2, 3, and 4, NUREG/CR5535, EGG-2596, June 1990.

3. K. E. Carlson, "Nitrogen Mass and Heat Transfer in ATHENA," 1993 RELAP5 International Users Seminar, Boston, MA, July 6-9, 1993.

4. R. P. Forslund and W. M. Rohsenow, "Dispersed Flow Film Boiling," Journal of Heat Transfer, November 1968.

5. J. E. Tolli, ATHENA MHD Model, EGG-SC-93-107, February 1993. 


\title{
TOKAMAK PHYSICS EXPERIMENT SAFETY ANALYSES AND ENVIRONMENTAL SAFETY \& HEALTH COMPLIANCE ACTIVITIES
}

\author{
Researchers: C. G. Motloch, INEL, M. A. McKenzie-Carter, SAIC, \\ J. C. Commander, Consultant, and J. D. Levine, PPPL
}

The Tokamak Physics Experiment (TPX) project is a new fusion energy initiative designed to make significant contributions toward achieving the goals of the U.S. fusion energy program. The purpose of the TPX project is to develop the scientific basis for a compact and continuously operating tokamak fusion reactor. ${ }^{.}$The TPX design is based on planned deuterium-deuterium (DD) operations. However, the design does not preclude future deuterium-tritium (DT) operations. The TPX project is presently planned to be located primarily inside the existing Tokamak Fusion Test Reactor (TFTR) test cell.

\section{Major Accomplishments}

In accordance with the provisions of the National Environmental Policy Act (NEPA) of 1969, we have been involved with preparation of an Environmental Assessment (EA) that conservatively assumes DT operations. Results indicate that the potential environmental impacts of TPX DT operations would bound those for DD operations.

The environmental impacts of two distinct projects proposed by the Department of Energy (DOE) are being evaluated in that EA. ${ }^{2}$ The first project is the TFTR Decontamination and Decommissioning (D\&D). The second project is the construction of the TPX. They are being evaluated in the same EA because the TPX project cannot proceed unless the TFTR D\&D is completed first (therefore, the projects are connected).

Based on an Action Description Memorandum (ADM) prepared by the TPX project, DOE directed the development of an EA in June
1992. From the analyses in the draft EA, we anticipate that a Finding of No Significant Impact (FONSI) will be issued by DOE.

The proposed TPX project action consists of the design, construction, and operation of the TPX project within the existing TFTR facility at the Princeton Plasma Physics Laboratory (PPPL). The proposed TPX would utilize existing PPPL utilities and TFTR support systems following completion of TFTR D\&D. New facility construction would include:

- $\quad$ TFTR test cell modifications

- Cryogenic equipment building

- Electrical substation

- Miscellaneous tank yards.

All new construction would take place on existing open space within the D-Site area at PPPL. The TPX would be designed to operate for approximately 10 years, beginning in approximately 2000 .

Alternatives to the proposed action include no action and an alternative site action, neither of which is preferred. A matrix showing the possible combinations of proposed actions and alternatives considered in the EA is given in Table 2. The TFTR D\&D no-action alternative and the TFTR D\&D delayed alternative could not be coupled with the proposed TPX project because of the prompt need for the TFTR test cell complex by the proposed TPX action. Similarly, the TPX no-action alternative and Oak Ridge Reservation (ORR) Site alternative would be unreasonable to couple with the proposed TFTR D\&D project, because neither 
Table 2. Proposed actions and alternatives for TFTR D\&D and TPX siting.

\begin{tabular}{llll}
\hline & \multicolumn{3}{c}{ TPX project } \\
\cline { 2 - 4 } TFTR D\&D & Proposed & No action & ORR site \\
\hline Proposed & Possible & $\begin{array}{l}\text { Unreasonable } \\
\text { combination }\end{array}$ & $\begin{array}{l}\text { Unreasonable } \\
\text { combination }\end{array}$ \\
No action & $\begin{array}{l}\text { Impossible } \\
\text { combination }\end{array}$ & Possible & Possible \\
Delayed & $\begin{array}{l}\text { Impossible } \\
\text { combination }\end{array}$ & Possible & Possible \\
\hline
\end{tabular}

of these TPX alternatives would require prompt use of the TFTR test cell complex, as required by the schedule for the proposed TPX project.

A methodology for assessing the consequences of radioactivity releases during normal operations of the TPX facility at PPPL has been developed ${ }^{3}$ and was used to support calculations in the EA. Potential radiological impacts of normal TPX operations at the TFTR Test Cell Complex will be minor and will not represent potential impacts greater than those from current PPPL operations. The TPX project has adopted a design objective dose of $100 \mu \mathrm{Sv}$ (10 mrem) per year as a maximum allowable individual dose to any member of the public. Occupational doses will not exceed the PPPL administrative limit of $10 \mathrm{mSv}$ (1 rem) per year. The small radioactive releases to the environment, as well as exposures and dose equivalents to the public and workers, will be well below acceptable DOE, State, and Federal standards.

Atmospheric releases of tritium and activation products constitute the only potential sources of airborne radiological exposure to members of the public. For tritium operations, and assuming normal availability of the Tritium Purification System (TPS), the projected atmospheric releases would result in an annual effective dose equivalent of $46 \mu \mathrm{Sv}$ (4.6 mrem) to a hypothetical maximally exposed individual at the site boundary. During deuterium operations, (without use of the TPS) the maximum atmospheric releases would result in an annual effective dose equivalent of $12 \mu \mathrm{Sv}$ (1.2 mrem). These conservatively calculated effective dose equivalents are less than the most restrictive limit for public doses caused by airborne releases (the EPA limit is $100 \mu \mathrm{Sv}$ [10 mrem] per year). Direct radiation from the TPX project would be mitigated with shielding to keep the total effective dose equivalent from all sources at the site boundary within the project design objective of $100 \mu \mathrm{Sv}$ (10 mrem) per year. This design objective effective dose equivalent is well below the DOE limit of $1 \mathrm{mSv}$ (100 mrem) per year to members of the public from routine DOE operations. The estimated maximum total annual individual dose to a member of the public from TPX operations (96 $\mu \mathrm{Sv}$ [9.6 mrem] from 1 year of tritium operations) would result in an increased probability of health effects of $4.8 \times 10^{6}$ per year $(4.8$ chances in $1,000,000)$.

Potential off-normal events and releases for the TPX have been assessed. ${ }^{4}$ Accidental releases of radioactive material could result from (a) natural phenomena (e.g., earthquakes), (b) accidents of external origin (e.g., airplane crashes), (c) shipping accidents (i.e., accidents involving the transportation of radioactive material), and (d) operational occurrences (e.g., tritium leaks). All TPX confinement boundaries 
would be capable of maintaining integrity for design-basis seismic events. Therefore, a release due to natural phenomena is extremely unlikely.

\section{Future Activities}

We plan to continue support of the TPX activity at PPPL by beginning a draft Preliminary Safety Analysis Report (PSAR). This must be completed before final design and construction of TPX. There will also be further activity in obtaining final approval of the EA prepared this fiscal year. 


\section{References}

1. Princeton Plasma Physics Laboratory, "TPX Conceptual Design Overview," TPX Conceptual Design Review, March 29 - April 1, 1993, 91-930323PPPL/WReiersen-01.

2. Draft Environmental Assessment: The Tokamak Fusion Test Reactor Decontamination and Decommissioning Project and the Tokamak Physics Experiment at the Princeton Plasma Physics Laboratory, DOE/EA-0813, DOE, August 2, 1993.

3. M. A. McKenzie-Carter and M. E. Anderson, Methodology for Assessing the Consequences of Radioactive Releases During Normal Operations of the TPX Facility, EGG-FSP-10868, July 1993.

4. L. C. Cadwallader and C. G. Motloch, Potential Off-Normal Events and Releases for the Tokamak Physics Experiment, EGG-FSP-10710, August 1993. 


\title{
ARIES TOKAMAK REACTOR DESIGN STUDY
}

\author{
J. S. Herring, T. J. Dolan, and K. A. McCarthy, INEL
}

For the last 5 years, we have been participating in the ARIES tokamak design study, primarily working to ensure the safety of the resulting reactors. The ARIES program has been very important to the overall fusion program in demonstrating the potential safety and environmental attractiveness of commercial fusion reactors. That attractiveness will not be apparent in the International Thermonuclear Experimental Reactor (ITER), which must use present-day materials.

\section{Major Accomplishments}

The ARIES-II and ARIES-IV designs complete the four visions of commercial tokamak fusion reactors in the ARIES study. The ARIES-II design incorporates several design features to reduce accident possibilities and consequences. Among these features are the use of liquid lithium and vanadium, both of which are low activation, multiple barriers between the lithium and air, and an inert cover gas to prevent lithium-air reactions. Preventing lithium-air reactions is very important because the primary energy source in the design is the liquid lithium. There is no water inside the containment building, thus lithium-water reactions are avoided. The ARIES-II reactor is passively safe, having a level of safety assurance (LSA) of 2 , with a total $1-\mathrm{km}$ early dose of about $0.88 \mathrm{~Sv}$. This dose is the result of a full-scale lithium fire resulting from a lossof-coolant accident (LOCA) with air ingress. To realize the $2 \mathrm{~Sv}$ goal, we were able to show that the release fraction of the reactor materials is less than $0.072 \%$. The ARIES-IV tokamak reactor has been designed to avoid the use of materials subject to neutron activation and materials that are energy sources for the release of those activation products that do occur. The coolant is helium, which will not activate and has only the mechanical energy from its $10-\mathrm{MPa}$ operating pressure. The breeder is lithium oxide. The structure of the first wall, blanket, and shield is silicon carbide, which has a very low neutron activation and is chemically inert. Since the breeder is a lithium compound rather than lithium metal, a neutron multiplier must be used. For the ARIES-IV design, beryllium metal is used for neutron multiplication. Since beryllium metal is combustible, releasing about $60 \mathrm{MJ} / \mathrm{kg}$, the multiplier is the chief source of chemical energy for the release of activation products in the structure. We can argue that less than $10 \%$ of the ${ }^{24} \mathrm{Na}$ inventory is likely to diffuse out of the silicon carbide during a fire in which the Be neutron multiplier is consumed. Therefore, the offsite dose would be less than $2 \mathrm{~Sv}$, and the reactor satisfies the condition for LSA $=1$.

THE ARIES-II DESIGN. Using liquid lithium as the breeding blanket material has some safety advantages over solid breeder designs. Among tritium breeders studied by Piet et al., ${ }^{1}$ elemental lithium is the lowest activation breeder and has low afterheat. Additionally, a multiplier is not necessary in this design; so beryllium, which is reactive, even when in the form of beryllium metal, and toxic in the nonmetal form, is not needed.

The following safety features are used in ARIES-II to minimize the hazard:

1. Low-Afterheat Structural Material. The present $\mathrm{V}-5 \mathrm{Cr}-5 \mathrm{Ti}$ alloy has a satisfactory LOCA afterheat temperature of $850^{\circ} \mathrm{C}$. This alloy was chosen partly because mechanical, thermal, and irradiation data are available. More advanced vanadium alloys with less titanium may be developed in the future to achieve lower afterheat.

2. Multiple Barriers Between Lithium and Air. For lithium within the vacuum chamber, the barriers are the lithium ducts, 
vacuum chamber, and reactor containment room. For lithium outside the vacuum chamber, there are two barriers, the lithium duct wall and containment room. A thin stainless steel outer shell could be used on the lithium ducts to provide a third barrier.

3. Cover Gas. An inert cover gas, such as argon, will fill the reactor containment room at a pressure slightly above atmospheric. This gas will prevent immediate contact of lithium with air. Sensitive instruments will be used to detect small leaks, which will result in argon going out, instead of air coming in. The torus should be designed to prevent argon access to high neutron flux regions during normal operation. This will help avoid argon activation. If argon activation is a serious problem, then nitrogen or helium could be considered. However, helium is expensive and nitrogen reacts mildly with lithium.

4. Exclusion of Water. Water will be excluded from the containment building, to prevent its contact with lithium.

5. Piping Connections. Making most connections above the torus helps to prevent a LOCA.

6. Steel Liner. The reactor room will have a steel liner, to prevent spilled lithium from coming in contact with concrete. The floor will be sloped so that large lithium spills run to drains connected to drain tanks.

7. Drain Tanks. Tubes below the torus lead to lithium drain tanks. During an emergency, the lithium could be drained rapidly into the tanks, with an inert atmosphere sealed by fire-retarding valves. This technology was developed for the Titan-I reactor design. ${ }^{2}$
8. Missile Impact. The turbine generators will be located well away and oriented so that ruptured turbine blades would not be aimed toward the reactor room. The hazard of aircraft impact could be reduced by locating the reactor room below grade.

9. Cover Materials. In the event of a spill and breach of containment, the lithium that does not run down the drains could be covered with an inert powder dropped from tanks inside the ceiling. This would minimize contact with air. For example, the powder could be hollow graphite microspheres that would float on top of liquid lithium. ${ }^{3}$

10. Aerosol Filtration. The containment room will be equipped with a filtration system capable of removing lithium-compound aerosols with greater than $99 \%$ efficiency. ${ }^{2}$

Vanadium Recycling. Vanadium alloys with selected alloying elements can have low residual long-term radioactivity, which will permit their recycling, provided that impurity levels are kept low. After irradiation and cooling, activated structural materials may either be recycled or consigned to permanent waste disposal. The choice will be based on costs, regulations, and political conditions.

The ARIES-IV Design. The ARIES-IV tokamak reactor has been designed to avoid the use of materials subject to neutron activation and materials that are energy sources for the release of those activations that do occur. The coolant is helium, which will not activate, and has very little energy other than that due to its $10 \mathrm{MPa}$ operating pressure. The breeder is lithium oxide, which is a low activation material. Also, lithium oxide will not chemically react with the containment atmosphere or the coolant. The structure of the first wall, blanket, and shield is silicon carbide, which has a very low neutron activation and is chemically inert. 
Because the breeder is a lithium compound rather than lithium metal, a neutron multiplier must be used. For the ARIES-IV design, beryllium metal is used for neutron multiplication. Because beryllium metal is combustible, releasing about $60 \mathrm{MJ} / \mathrm{kg}$, the multiplier is the chief source of chemical energy for the release of activation in the structure. Beryllium oxide would have been preferable from a safety standpoint since that oxide is very inert, but the blanket would not have had a sufficient breeding ratio using a beryllium oxide multiplier. Since Be is electrically conducting, it also serves as a passive plasma stabilization coil, preventing kink instabilities.

Beryllium in a respirable form is toxic, at least to a portion of the population. Therefore, an evacuation plan will be needed for the area surrounding the reactor.

Radionuclide Inventorles. Silicon carbide is a low activation material because the radionuclides produced by neutron irradiation are either stable or have very short half-lives.

The offsite doses are dominated by ${ }^{24} \mathrm{Na}$. Sodium is both chemically and biologically active, resulting in a relatively high dose per becquerel released. Furthermore, since ${ }^{24} \mathrm{Na}$ has a half-life of 15 hours, it cannot be assumed to decay significantly during its transport out of the reactor and to the site boundary. ${ }^{24} \mathrm{Na}$ is produced in silicon carbide through a two-step reaction, ${ }^{28} \mathrm{Si}(\mathrm{n}, \mathrm{d}){ }^{27} \mathrm{Al}$ [stable] $(\mathrm{n}, \alpha){ }^{24} \mathrm{Na}(\beta$, $14.97 \mathrm{hr}$ ).

The chief radionuclide of concern in the ARIES-IV design is the ${ }^{24} \mathrm{Na}$, resulting from a two-step activation of ${ }^{28} \mathrm{Si}$. Data for the diffusion of sodium through silicon carbide at elevated temperatures have not been found.
We have evaluated the diffusion of several elements through both silicon and silicon carbide. We estimated the diffusion of sodium through silicon carbide based on these data.

Based on this diffusion, we argue that less than $10 \%$ of the ${ }^{24} \mathrm{Na}$ inventory is likely to diffuse out of the silicon carbide during a fire in which the beryllium neutron multiplier is consumed. Note that other radionuclides present in the silicon carbide would diffuse more slowly through silicon carbide than sodium.

Since the release fraction of the dominant isotope ${ }^{24} \mathrm{Na}$ is less than about 10\%, the offsite dose would be less than $2 \mathrm{~Sv}$, and the reactor satisfies the condition for LSA $=1$. This conclusion could be invalidated if the four assumptions shown above are not valid.

\section{Future Activities}

The Fusion Safety Program will continue to participate in PULSAR (a pulsed version of the steady-state ARIES conceptual design study), DEMO (a power-producing prototype design study), and other follow-on studies by applying INEL research to fusion reactor designs in activation product release, tritium transport, dose calculations, and accident data. We will broaden the role of the safety task to anticipate the public acceptance issues that fusion will eventually face. We are participating in the PULSAR design study by identifying issues unique to pulsed operation, determining the importance of $\mathrm{SiC}$ impurities, exploring the implications of ${ }^{29} \mathrm{Si}(\mathrm{n}, \mathrm{t})^{27} \mathrm{Al}$ reaction, and establishing evacuation requirements for future designs.

We are also participating in current stellarator design studies, providing input on safety and environmental aspects. 


\section{References}

1. S. J. Piet et al., Accident Safety Comparison of Elements to Define Low Activation Materials, EOG-FSP-8552, July 1989.

2. F. Najmabadi, R. W. Conn, N. Ghoniem et al., The Titan Reversed-Field-Pinch Fusion Reactor Stucty, Final Report, UCLA-PPG-1200, 1990.

3. J. A. Blink, O. H. Krikorian, and N. J. Hoffman, The Use of Lithium in Fusion Reactors, UCRL-85145, 1981. 
Appendix A

Abstracts or Summaries of Fusion Safety Program Publications 


\section{Appendix A}

\section{Abstracts or Summaries of Fusion Safety Program Publications}

\section{ITER Design and Regulatory Support}

Requirements for U.S. Regulatory Approval of the International Thermonuclear Experimental Reactor (ITER)

David A. Petti and J. Curtis Haire, IEEE/NPSS, 15th Symposium on

Fusion Engineering, Hyannis, MA, October 11-15, 1993.

This paper presents an overview of the requirements for U.S. regulatory approval of the International Thermonuclear Experimental Reactor (ITER). An overview of facility life cycle phases that must be considered in the regulatory approval process is presented, concentrating on those early phases that most impact ITER. DOE radiation protection criteria are presented to provide key dose limits that would impact the ITER design. In addition, three of the many nuclear safety-related technical issues - verification and validation of computer codes, safety class items, and experimental databases needed for regulatory approval - are discussed because of their impact on ITER safety, R\&D, and design activities. Finally, general guidelines concerning the development of a regulatory framework for ITER are presented and recommendations are formulated.
Fusion Power Economy of Scale T. J. Dolan, Fusion Technology, 24, pp. 97-111, 1993.

In the next 50 years, the world will need to develop hundreds of gigawatts of nonfossil-fuel energy sources for production of electricity and fuels. Nuclear fusion can probably provide much of the required energy economically, if large single-unit power plants are acceptable. There are already many multiple-unit power plants producing 2-5 GWe at a single site. The cost of electricity (COE) from fusion energy is predicted to scale as $\operatorname{COE} \approx \operatorname{COE}_{0}\left(\mathrm{P} / \mathrm{P}_{\mathrm{o}}\right)^{- \text {n}}$, where $\mathbf{P}=$ electrical power, the subscripts o denote referenci values, and the exponent $\mathrm{n} \approx 0.36-0.7$ in various designs. The validity ranges of these scalings are limited and need to be extended by future work. The fusion power economy of scale derives from four interreiated effects: improved operations and maintenance costs, scaling of equipment unit costs, a geometric effect increasing the mass power density, and reduction of the recirculating power fraction. Increased plasma size also relaxes the required confinement parameters: for the same neutron wall loading, larger tokamaks can use lower magnetic fields. Fossil fuel power plants have a weaker economy of scale than fusion, because the fuel costs constitute much of their COE. Solar and wind power plants consist of many small units, so they have little economy of scale. Fission power plants have a strong economy of scale, but are unable to exploit it, because the maximum unit size is limited by safety concerns. Large, steady-state fusion reactors generating 3-6 GWe may be able to produce electricity for $4-5$ cents/ $/ \mathrm{kWh}$, which would be competitive with other future energy sources. 


\section{Tritium Safety}

\section{A Simplified Model for Tritium Permeation Transient Predictions when Trapping is Active}

G. R. Longhurst, Sixth International

Conference on Fusion Reactor

Materials, Stresa, Italy, September 27 October 4, 1993; also EGG-FSP-10960, September 1993.

This report describes a simplified onedimensional tritium permeation and retention model. The model makes use of the same physical mechanisms as more sophisticated, time-transient codes such as implantation, recombination, diffusion, trapping and thermal gradient effects. It takes advantage of a number of simplifications and approximations to solve the steady-state problem and then provides interpolating functions to make estimates of intermediate states based on the steady-state solution. Comparison calculations are provided with the verified and validated TMAP4 transient code with good agreement.

\author{
Meeting Summary, IAEA Technical \\ Committee Meeting on Developments \\ in Fusion Safety, Toronto, Canada, \\ June 7-11, 1993 \\ T. J. Dolan, Fusion Technology (to be \\ published).
}

The International Atomic Energy Agency (IAEA) Technical Committee Meeting on Developments in Fusion Safety was held June 7-11, 1993 in Toronto Canada, and was hosted by the Canadian Fusion Fuels Technology Project (CFFTP). The meeting was chaired by G. A. Vivian, CFFTP. The program, consisting of 38 papers and two panel discussions, was attended by 56 fusion reactor safety specialists from around the world. The proceedings will be published in the Journal of Fusion Energy.

The strong emphasis given to safety is a credit to the IAEA and ITER leadership. By the next meeting in this series (in about 1996, possibly in Japan) the ITER Engineering Design Activity (EDA) will have determined the major ITER parameters, and the safety analyses will be more refined. International cooperation, as exemplified by this meeting, will help guide the ITER project toward an experiment that can win public confidence. Optimization of safety may be crucial to the successful development of fusion power. 
HYLIFE-II Tritium Management System

G. R. Longhurst and T. J. Dolan, EGG-FSP-9971, June 1993.

The tritium management system performs seven functions: (1) tritium gas removal from the blast chamber, (2) tritium removal from the mixture of lithium fluoride and beryllium fluoride called flibe, (3) tritium removal from helium sweep gas, (4) tritium removal from room air, (5) hydrogen isotope separation, (6) release of nonhazardous gases through the stack, and (7) fixation and disposal of hazardous effluents. About $2 \mathrm{TBq} / \mathrm{s}(5 \mathrm{MCi} /$ day $)$ of tritium is bred in the Flibe $\left(\mathrm{Li}_{2} \mathrm{BeF}_{4}\right)$ molten salt coolant by neutron absorption. Tritium removal is accomplished by a two-stage vacuum disengager in each of three steam generator loops. Each stage consists of a spray of 0.4$\mathrm{mm}$ diameter hot Flibe droplets into a vacuum chamber $4 \mathrm{~m}$ in diameter and $7 \mathrm{~m}$ tall. As droplets fall downward into the vacuum, most of the tritium diffuses out and is pumped away. $A$ fraction, $F \approx 10^{-5}$, of the tritium remains in the Flibe as it leaves the second stage of the vacuum disengager, and about $24 \%$ of the remaining tritium penetrates through the steam generator tubes, per pass, so the net leakage into the steam system is about $4.7 \mathrm{MBq} / \mathrm{s}$ (11 $\mathrm{Ci} /$ day). The required Flibe pumping power for the vacuum disengager system is $6.6 \mathrm{MW}$. With Flibe primary coolant and a vacuum disengager, an intermediate coolant loop is not needed to prevent tritium from leaking into the steam system. An experiment is needed to demonstrate vacuum disengager operation with Flibe. A secondary containment shell with helium sweep gas captures the tritium permeating out of the Flibe ducts, limiting leaks to about $1 \mathrm{Ci} / \mathrm{day}$. The tritium inventory in the reactor is about $190 \mathrm{~g}$, residing mostly in the large Flibe recirculation duct walls. Total cost of the tritium management system is $\$ 92$ million, of which the vacuum disengagers cost $56 \%$, the blast chamber vacuum system $15 \%$, the cryogenic plant $9 \%$, the emergency air cleanup and waste treatment systems each $6 \%$, the protium removal system $3 \%$, and the fuel storage system and inert gas system each $2 \%$. 


\section{Environmental Tritium Transport Monitoring at TFTR \\ P. D. Ritter, T. J. Dolan, and G. R. Longhurst, Joumal of Fusion Energy, 12, pp. 379-382, 1993.}

Environmental tritium concentrations will be measured near the Tokamak Fusion Test Reactor (TFTR) to help validate dynamic models of tritium transport in the environment. For model validation, the database must contain sequential measurements of tritium concentrations in key environmental compartments. Since complete containment of tritium is an operational goal, the supplementary monitoring program should be able to glean useful data from an unscheduled acute release or from a very low-level chronic release. Portable air samplers will be used to take samples automatically every 4 hours for a week after an acute release, thus obtaining the time resolution needed for code validation. Samples of soil, vegetation, and foodstuffs will be gathered daily at the same locations as the active air monitors. The database may help validate the plant/soil/air part of tritium transport models and enhance environmental tritium transport understanding for the International Thermonuclear Experimental Reactor (ITER).
Hydrogen Permeation Properties of Plasma-Sprayed Tungsten

R. A. Anderl, R. J. Pawelko, M. R. Hankins G. R. Longhurst, R. A. Neiser, 6th International Conference on Fusion Reactor Materials, Stresa (VA), Italy, September 27 - October 1, 1993.

Tungsten has been proposed as a plasmafacing component material for advanced fusion facilities. This paper reports on laboratoryscale studies to assess the hydrogen permeation properties of plasma-sprayed tungsten for such applications. The work entailed deuterium permeation measurements for plasma-sprayed (PS) tungsten coatings, sputter-deposited (SP) tungsten coatings, and steel substrate material using a mass-analyzed, 3-keV $\mathrm{D}_{3}^{+}$ion beam with fluxes of $\approx 6.5 \times 10^{19} \mathrm{D} /\left(\mathrm{m}^{2}-\mathrm{s}\right)$. Extensive characterization analyses for the plasma-sprayed tungsten coatings were made using Auger spectrometry and scanning electron microscopy (SEM). Observed permeation rates through composite PS-tungsten/steel specimens were several orders of magnitude below the permeation levels observed for SP-tungsten/steel composite specimens and pure steel specimens. Characterization analyses indicated that the plasma-sprayed tungsten coating had a nonhomogeneous microstructure that consisted of splats with columnar solidification, partiallymelted particles with grain boundaries, and void regions. Reduced permeation levels can be attributed to the complex microstructure and a substantial surface-connected porosity. 
Using the Tritium Plasma Experiment to Evaluate ITER PFC Safety

G. R. Longhurst, Journal of Fusion

Energy, 12, pp. 349-353, 1993.

The Tritium Plasma Experiment was assembled at Sandia National Laboratories, Livermore, and is being moved to the Tritium Systems Test Assembly facility at Los Alamos National Laboratory to investigate interactions between dense plasmas at low energies and plasma-facing component materials. This apparatus has the unique capability of replicating plasma conditions in a tokamak divertor with particle flux densities of $2 \times 10^{19}$ ions $/ \mathrm{cm}^{2} . s$ and a plasma temperature of about $15 \mathrm{eV}$ using a plasma that includes tritium. An experimental program has been initiated using the Tritium Plasma Experiment to examine safety issues related to tritium in plasma-facing components, particularly the ITER divertor. Those issues include tritium retention and release characteristics, tritium permeation rates and transient times to coolant streams, surface modification and erosion by the plasma, the effects of thermal loads and cycling, and particulate production. An industrial consortium led by MDC Aerospace will design and fabricate the test fixtures. 


\section{Beryllium Safety}

Research of Beryllium Safety Issues G. R. Longhurst, R. A. Anderl, T. J. Dolan, M. R. Hankins, and R. J. Pawelko, International Workshop on Beryllium Technology for Fusion Applications, Karlsruhe, Germany, October 4-5, 1993.

Beryllium has been identified as a leading contender for the plasma-facing material in ITER. Its use has some obvious advantages, but there are also a number of safety concerns associated with beryllium. The Idaho National Engineering Laboratory (INEL) has undertaken a number of studies to help resolve some of these concerns. One concern is the response of beryllium to neutron irradiation. We have tested samples irradiated in the Advanced Test Reactor (ATR) and are currently preparing to make measurements of the change in mechanical properties of beryllium samples irradiated at elevated temperatures in the Fast Flux Test Facility (FFTF) and the Experimental Breeder Reactor II (EBR-II) at the INEL. Mechanical tests will be conducted at irradiation temperatures of $375-550^{\circ} \mathrm{C}$. Other experiments address permeation and retention of implanted tritium in plasma-sprayed beryllium. In one test the porosity of the material allowed $0.12 \%$ of implanted ions and $0.17 \%$ of atoms from background gas pressure to pass through the foil with essentially no delay. For comparison, similar tests on fully dense hot-rolled, vacuum melted or sintered powder foils of high purity beryllium showed only $0.001 \%$ of implanting ions to pass through the foil, and then only after a delay of several hours. None of the molecular gas appeared to permeate these latter targets. An implication is that plasma-sprayed beryllium may substantially enhance recycling of tritium to the plasma, provided it is affixed to a relatively impermeable substrate. To further evaluate safety issues associated with tritium interaction with beryllium, the Tritium Plasma Experiment (TPE) is being assembled at Los Alamos National Laboratory after its first installation at Sandia National Laboratories, Livermore. This test apparatus will enable testing under full-scale divertor conditions. The first experiments in that facility will examine tritium retention and permeation in a beryllium duplex structure. Test plans are now being formulated for a project that involves several laboratories and industrial participants. 


\section{Low Activation Materials}

Safoty and Environmental Aspects of Vanadium Alloys

G. J. Butterworth, K. A. McCarthy, G. R. Smolik, and C. B. A. Forty, Sixth International Conference on Fusion Reactor Materials, Stresa, Italy, September 27 - October 1, 1993.

Two important safety-related and environmental aspects of vanadium alloys are considered: the early doses that could potentially be delivered at the plant site boundary in the event of an accidental release of first wall material, and the disposal and recycling options for expired first wall-blanket material. The reference alloys $\mathrm{V}-15 \mathrm{Cr}-15 \mathrm{Ti}$ and $\mathrm{V}-3 \mathrm{Ti}-1 \mathrm{Si}$ are found to lead to similar doses, and these doses are roughly an order of magnitude below the dose from $316 \mathrm{~L}$ steel. These alloys appear to be excellent candidates for multiple recycling via high-vacuum remelting/refining, with consequent reductions in the consumption of alloy and in the quantities of waste requiring geological isolation. The doses from accidental releases are found to be independent of the number of usage cycles.
Safoty and Environmental Aspects of Fusion Power

K. A. McCarthy, Project Energy '93, Kansas City, Missouri, June 21-23, 1993.

Fusion power has the potential to be a safe and environmentally friendly energy source. Materials and design can limit hazards from accidental release of radioactive material and minimize waste disposal problems. In addition, no emissions are produced to degrade visibility, increase greenhouse gases, cause acid rain, or reduce the ozone layer. Because of the flexibility in materials choice, recycling and near-surface burial are potential options for radioactive waste management. 


\section{Activation Product Chemical Reactivity, Volatility, and Transport}

Characterization of Oxide Breakup by Convective Currents

G. R. Smolik, K. A. McCarthy, and V. L. Smith-Wackerle, 15th Symposium on

Fusion Engineering, Hyannis, MA, October 11-15, 1993.

One safety consideration for fusion reactors is the potential release of activated products during a loss-of-coolant accident (LOCA). In this paper, we address the relative role that small, airborne particles, formed by convective current transport and grinding of spalled oxides, may have in predicted releases. We describe the methodology developed to measure the attrition of oxide particles when they are transported in a gas stream. This method has been used to measure the tendency for small "airborne size" particles to form from oxides of a tungsten alloy, a niobium alloy, and a ferritic steel (HT9). We have used these data to compare the magnitudes of elemental releases that may occur by volatilization with those releases due to the oxide attrition pathway for the tungsten and niobium alloys oxidized in air. Oxide attrition provides significant releases of tungsten and is the dominant mechanism in the release of niobium. These results show that oxide attrition should be considered in safety evaluations and that additional testing is warranted for other materials, such as beryllium, austenitic stainless steel (primary candidate alloy [PCA]), and vanadium alloys. Data are also needed for oxides formed in other environments and at other temperatures to establish a database that will allow mapping of dominant release mechanisms for the complex thermal cycles that could exist during a LOCA. 


\section{Liquid Metal Chemical Reactions}

Incorporation of a Simplified Hydrogen Generation Scheme Into the 1-D Hydrodynamic Model, TEXAS-III

John G. Murphy, University of Wisconsin Master's Thesis, April 1993.

During a loss-of-coolant accident (LOCA) in the core of a water-cooled reactor, fission product decay could eventually cause the reactor fuel and cladding to melt. This molten core material is sometimes called corium and is composed of certain fractions of fissionable fuel, cladding, and structural steel. The corium, which contains unoxidized metal, may come in contact with water, either in the lower plenum, or, if the vessel wall fails, in the reactor cavity itself. If corium falls into water, a fuel/coolant interaction (FCI) will take place, with the additional probability that hydrogen will be generated by the oxidation of the metal with water vapor. In a related sense, future fusion reactor designs will probably incorporate water as a secondary side heat transfer agent. With a liquid metal (lithium or lithium alloys), as the most likely candidate for coolant and breeding, the potential exists, through a heat exchanger leak or a metal spill, for an FCI-type accident scenario with fusion systems. In both cases, the FCI can lead to the production of large quantities of steam and hydrogen that can cause containment overpressurization. The hydrogen generated poses an additional threat from subsequent hydrogen combustion. Using a simplified hydrogen generation model for FCIs and incorporating it into an existing 1-D hydrodynamic model, TEXAS, hydrogen production levels can be calculated for metal/water interactions (e.g., molten aluminum). The objective is to develop an improved model that better characterizes the fuel/coolant mixing process with hydrogen generation for metal/water interactions.

\section{Liquid-MetalWater Interactions in a} Shock-Tube Geometry

G. Vukovic and M. L. Corradini, National Heat Transfer Conference, Atlanta, Georgia, August 10, 1993.

A vertical shock tube has been designed and constructed for investigations of liquidmetal (fuel)/water interactions. A series of tests with gallium, indium, lead and tin were performed in fuel temperature ranges of 300 $600^{\circ} \mathrm{C}$, with water at room temperature and in the range of $60-70^{\circ} \mathrm{C}$, and with driving pressures from 2.5 to 12 bar. These tests are the initial results from a group of tests that will be extended to other materials (lead alloys, aluminum, and its alloys) and higher temperatures $\left(\sim 1200^{\circ} \mathrm{C}\right)$.

Preliminary information was gathered on thermal-hydraulic behavior of interactions. During the experiments, the temperatures and dynamic pressures were measured along the tube, as well as the initial driving pressure. From the measured parameters, the initial impact energy and mechanical energy release of the fuel/coolant interaction were calculated. As expected, the increase in fuel and water temperature, as well as the increase of driving pressure, caused more energetic interactions. Tin and lead thermal interactions at high temperatures were the most energetic. In high-temperature gallium and indium interactions with water, small oxidation was observed. In none of these initial results were significant chemical reactions observed. 


\section{Risk Assessment}

Failure Rate Data for Glove-Box Components and Cleanup Systems at the Tritium Systems Test Assembly

L. C. Cadwallader and G. L. Taylor, Journal of Fusion Energy, 12, pp. 281285, 1993.

Fusion facility safety and reliability/ availability analyses require accurate component failure rate information to provide meaningful results. While fission reactor operating experience data may be adequate for some types of components, there are some data needs that are fusion-specific, such as tritium fueling and handling system information. This paper summarizes data analysis of tritium glove-box confinement systems and an air detritiation system from the Tritium Systems Test Assembly (TSTA) at Los Alamos National Laboratory. These analyses benefit fusion work by highlighting weak areas in designs to allow for modifications and upgrades, making future designs more robust. The TSTA results are generally smaller failure rates than this other information, thus showing the benefits of gathering these fusion-specific data.
Fallure Rate Data for Fusion Safety and Risk Assessment

L. C. Cadwallader, presented at the Subgroup Meeting on Data Banks for Risk Assessment, sponsored by the Safety Analysis Working Group of the Energy Facility Contractors Group (EFCOG), Augusta, Georgia, February 2-3, 1993.

The Fusion Safety Program at the Idaho National Engineering Laboratory conducts safety research in material chemical reactions, safety analysis, risk assessment, and component research and development to support existing magnetic fusion experiments and to promote safety in the design of future experiments. One of the areas of safety research is applying probabilistic risk assessment (PRA) methods to fusion experiments. To apply PRA, we need a fusion-relevant radiological dose code and a component failure rate database. This paper describes the Fusion Safety Program effort to develop a failure rate database for fusionspecific components. 
Experimental Tritium Cleanup System Avallability Analysis from 1984 to 1992

L. C. Cadwallader and G. L. Taylor, EGG-FSP-10603, May 1993.

This report gives the availability percentage of the Experimental Tritium Cleanup (ETC) system at the Tritium Systems Test Assembly (TSTA), which is a fusion research and technology facility at Los Alamos National Laboratory. The component failure reports, number of components, and operating times or demands are all given in this report. Sample calculations of the failure rates obtained from these data are given in the appendices. While future fusion experiments might use different or more advanced means to detritiate room air, the analysis of this system gives a data point for an actual detritiation system. Such a data point can be extrapolated for comparison with fault-tree analysis results on system designs, or can be used in a Bayesian failure rate analysis for estimating reliability of a new type of system. The 9 years of testing operations on TSTA's ETC result in a reasonable average availability value of $92 \%$ for the maximal tritium release event. The failure rates for new systems are expected to be lower than failure rates for the TSTA ETC, since improvements will be made in the design of a room air detritiation system based on TSTA experiences. Nonetheless, these TSTA data should be useful for future fusion reactor design and safety assessment tasks.
Dose Calculations for Accldental Airborne Releases of ITER Activation Products

M. L. Abbott, S. L. Harms, and A. S. Rood, EGG-EEL-10994, Draft, September 1993.

Radiological dose calculations were performed for $1 \mathrm{TBq}$ atmospheric release of 523 different radionuclides to support the International Thermonuclear Experimental Reactor (ITER) Engineering Design Activity (EDA). Doses were calculated using a new version of the MELCOR Accident Consequence Code System (MACCS2), which has been revised to evaluate potential accidental impacts at U.S. Department of Energy (DOE) facilities. Three general release and meteorological transport cases were modeled to evaluate two bounding worst-case conditions (with and without rain) and more typical less-conservative conditions. Dose impacts were evaluated for a maximally exposed individual (MEI) member of the public located $2 \mathrm{~km}$ from the release point and for an average population $\left(100 / \mathrm{km}^{2}\right)$ from $2-100 \mathrm{~km}$ from the release point. In addition, ground-level air concentrations normalized to source strength (chi/Q values) were calculated for each radionuclide for 18 distances ranging from $0.1-80 \mathrm{~km}$. The chi/Q values are used with the $2-\mathrm{km}$ dose results to estimate relative MEI dose impacts at each of the 18 downwind distances. The dose results and chi/ $Q$ values have been incorporated into an electronic spreadsheet program ("scoping tool") that allows a user to quickly retrieve various dose results for selected materials under different release, atmospheric dispersion, and receptor exposure conditions. 
COMIDA: A Radionuclldo FoodChaln Model for Acuts Fallout Doposition

M. L. Abbott and A. S. Rood, accepted for publication in Health Physics, May 7 . 1993; and report EGG-GEO-10367, November 1993.

A dynamic food-chain model/computer code named COMIDA has been developed to estimate radionuclide concentrations in agricultural food products following an acute fallout event. COMIDA estimates yearly harvest concentrations for 5 human crop types $(\mathrm{Bq} / \mathrm{kg}$ crop per $\mathrm{Bq} / \mathrm{m}$ deposited) and integrated concentrations for four annual animal products $(\mathrm{Bq}-\mathrm{d} / \mathrm{kg}$ animal product per $\mathrm{Bq} / \mathrm{m}$ ) for a unit deposition that occurs on any user-specified day of the year. COMIDA is structurally very similar to the PATHWAY model and includes the same seasonal transport processes and discrete events for soil and vegetation compartments. Animal product assimilation is modeled using simpler equilibrium models. Differential transport and ingrowth of up to three radioactive progeny are also evaluated. Benchmark results between COMIDA and PATHWAY for monthly fallout events show very similar seasonal agreement for integrated concentrations in milk and beef. Benchmark results between COMIDA and four international steady-state models show good agreement for deposition events that occur during the middle of the growing season. COMIDA will be implemented in the new Department of Energy (DOE) version of the MELCOR Accident Consequence Code System (MACCS2) for evaluation of accidental releases from nuclear power plants. 


\section{Magnet Safoty Research}

Quench in Suporconducting

Magnote, Part l: Modal and Numerical Implomentation

A. Shajil and J. P. Freidberg, PFC/JA93-10, Plasma Fusion Center, Massachusetts Institute of Technology. July 1993.

A new compact theoretical model is presented that describes the phenomena of quench propagation in cable in conduit superconducting magnets. The model circumvents many difficulties associated with obtaining numerical solution of more general existing models. Specifically, a factor of 30 50 is gained in the computational time required to study typical quench events. The corresponding numerical implementation of the new model is described, and the numerical results are shown to agree very well with those of the more general models, as well as with experimental data. 


\section{ATHENA Development}

Nitrogen Mass and Hoat Transfor in ATHENA

K. E. Carlson, 1993 RELAP5 International Users Seminar, Boston, MA, July 6-9, 1993.

Recently, the ATHENA heat transfer package was modified to use correlations proposed by Forslund to better simulate the dispersed film boiling regime. Results from this work indicated that mass transfer was very important in this regime and that additional investigation into the effects of the mass transfer model was required. This paper documents the investigation into the liquid nitrogen mass and heat transfer package in ATHENA/MOD1, with emphasis on the mass transfer model. The current ATHENA mass and wall heat transfer package is discussed first, followed by the Forslund model. Results from code simulations of the Forslund experiment are given next; and tinally, conclusions are presented.
ATHENA MHD Modal

J. E. Tolli, EGG-SC-93-107, February 1993.

A model to calculate the pressure drop due to magnetohydrodynamic (MHD) effects in liquid metal systems has been added to the ATHENA/MOD1 program. Based partly on theory and partly on experimental data from ALEX, this model is applicable to both circular and square duct geometries with either constant or spatially varying magnetic fields. This report describes the MHD pressure drop model, how it was incorporated into ATHENA's momentum equations, the required user input, a comparison between ATHENA predictions and ALEX data, and the Fortran coding of this model. 


\section{TFTR/PX Support}

Tokamak Physics Experiment Safoty Analyses and Environmental Safoty and Health Compliance Actlvities

C. G. Motloch, M. A. McKenzie-Carter, J. C. Commander, and J. D. Levine, IEEE/NPSS 15th Symposium on Fusion Engineering, Hyannis, MA, October 1115, 1993.

The Tokamak Physics Experiment (TPX) is a new fusion machine proposed to be built at the Princeton Plasma Physics Laboratory (PPPL). This paper describes results of the ongoing safety analyses and environmental, safety, and health (ES\&H) activities in support of this project. The TPX deuterium and tritium operation perspectives, radiological design objectives, results of dose calculations for normal and postulated accident scenarios, and nonradiological impacts are all addressed. As part of the ES\&H considerations, this paper provides an overview of the TPX Environmental Assessment (EA), the EA approval process, and a brief discussion of other environmental issues being addressed for TPX. Results show thrt nonradiological impacts are minor; operatioual and accidental releases of tritium, activated gases, or activated solids are within design objectives and regulatory limits; and TPX can be designed, constructed, and operated to meet all regulatory requirements.
Mothodology for Assessing the Consequences of Radioactive Releases During Normal Operations of the TPX Facillity at PPPL

M. A. McKenzie-Carter, M. E. Anderson, EGG-FSP-10868, July 1993.

This report contains information to support the combined Environmental Assessment for the Tokamak Fusion Test Reactor (TFTR) Decontamination and Decommissioning (D\&D) project and the Tokamak Physics Experiment (TPX), both proposed for the Princeton Plasma Physics Laboratory (PPPL). The assumptions and methodology used to assess the impact to members of the public from normal operational releases of radioactive material from the proposed TPX during the operational period are described. A description of the tracer release tests conducted at PPPL by NOAA is included; dispersion values from these tests are used in the dose calculations. Radiological releases, doses, and resulting health risks are calculated and summarized. The computer code CAP88-PC is used to calculate the individual and population doses for routine releases. Where applicable, doses are compared to regulatory limits and guideline values. 
Accident Risk Assessment of Safe Shutdown, Decontamination and Decommissioning of the Tokamak Fusion Test Reactor

H. J. Reilly and J. C. Commander, EGG-FSP-10868, July 1993.

This accident risk assessment of operations during TFTR Safe Shutdown and D\&D indicates very small accident frequencies and consequences to the public and to site workers. During the Safe Shutdown period, estimated risks will be smaller than they will have been during D-T operation, because the tokamak will not be operating and facility operations will be limited to a few of the same operations conducted during D-T, which have already been shown (DOE-1992) to have an acceptably small risk. During D\&D, risks will be small because all mobile hazardous inventories will have been removed, there will be a minimal amount of potential energy sources within the facility, and facility confinement systems will remain operational throughout D\&D operations. Remaining inventories will consist principally of radioactive solid components; most cutting and welding operations on those components will be conducted remotely inside confinement control envelopes.

Estimated doses for most identified accident scenarios are $10 \mu \mathrm{Sv}(1 \mathrm{mrem})$ or less for workers and fractions of that for members of the public. The highest consequence beyond design basis event is an unmitigated ground-level release of $92.5 \mathrm{TBq}$ $(25 \mathrm{kCi})$ of HTO. This event is assumed to occur as a result of air ingress onto a tritium generator, assuming concurrent failure of confinement, cleanup, and exhaust fans. This event has estimated frequency less than $1 \mathrm{E}-6 / \mathrm{yr}$ and could result in a dose as much as $3.9 \mathrm{mSv}$ (390 mrem) to the maximally exposed member of the public.

\section{Potential Off-Normal Events and Releases for the Tokamak Physics Experiment}

L. C. Cadwallader and C. G. Motloch, EGG-FSP-10710, August 1993.

The Tokamak Physics Experiment (TPX), featuring a steady-state advanced tokamak, is considered to be the next step in the United States' program to develop the commercial application of fusion power. The TPX is being designed to extend tokamak operation into the steady-state regime and to demonstrate the scientific basis for compact tokamak performance. It is to be constructed near Princeton, New Jersey in the existing Tokamak Fusion Test Reactor (TFTR) test cell, after decontamination and decommissioning (D\&D) of the TFTR. To address the environmental impact and public safety concerns of TPX operation, a preliminary analysis of potential off-normal radiological and hazardous material releases has been performed. Operational occurrences, natural phenomena, onsite accidents with external origins, and accidents external to the Princeton Plasma Physics Laboratory (PPPL) were considered as potential sources for offnormal events. Based on an initial screening, maximal-release events were selected for preliminary analysis. Included in these events were tritium releases from the tritium delivery and purification systems, tritium releases from the torus, releases of activated gases from the test cell or cryostat, releases of activated solid material, beryllium hazardous material releases, seismic events, and shipping cask accidents. In each case, the design considerations and release scenarios related to the event were reviewed and discussed. Because of the complexity of some of the postulated accident scenarios, event trees were frequently used to describe the scenarios. For each scenario, the frequency was estimated together with the release magnitude, isotope, chemical form, and release mode. 


\section{ARIES/PULSAR Tokamak Design Studies}

Safety Analyses of the ARIES-II and ARIES-IV Tokamak Reactor Designs J. S. Herring, K. A. McCarthy, and T. J. Dolan, IEEE/NPSS 15th Symposium on Fusion Engineering, Hyannis, MA, October 11-15, 1993.

The ARIES-II and ARIES-IV designs complete four visions of commercial fusion in the ARIES study. The ARIES-II design incorporates several design features to reduce accident possibilities and consequences. Among these features are (a) the use of liquid lithium and vanadium, both of which are low activation, (b) multiple barriers between the lithium and air, and (c) an inert cover gas to prevent lithium-air reactions. Preventing lithium-air reactions is very important because the primary energy source in the design is liquid lithium. There is no water inside the containment building, thus lithium-water reactions are avoided. The ARIES-II reactor is passively safe (level of safety assurance of 2) with a total $1-\mathrm{km}$ early dose of about $0.88 \mathrm{~Sv}$. This dose is the result of a full-scale lithium fire resulting from a LOCA with air ingress. To realize the 2-Sv goal, we were able to show that the release fraction of the reactor materials is less than $0.072 \%$. The ARIES-IV tokamak reactor has been designed to avoid the use of materials subject to neutron activation and materials that are energy sources for the release of those activation products which do occur. The coolant is helium, which will not activate and has only mechanical energy from $10 \mathrm{MPa}$ operating pressure. The breeder is lithium oxide. The structure of the first wall, blanket, and shield is silicon carbide, which has a very low neutron activation and is chemically inert. Since the breeder is a lithium compound rather than lithium metal, a neutron multiplier must be used. For the ARIES-IV design, beryllium metal is used for neutron multiplication. Since beryllium metal is combustible, releasing about $60 \mathrm{MJ} / \mathrm{kg}$, the multiplier is the chief source of chemical energy for the release of activation products in the structure. We can argue that less than $10 \%$ of the ${ }^{24} \mathrm{Na}$ inventory is likely to diffuse out of the $\mathrm{SiC}$ during a fire in which the Be neutron multiplier is consumed. Therefore, the offsite dose would be less than $2 \mathrm{~Sv}$, and the reactor satisfies the condition for $\mathrm{LSA}=1$. 

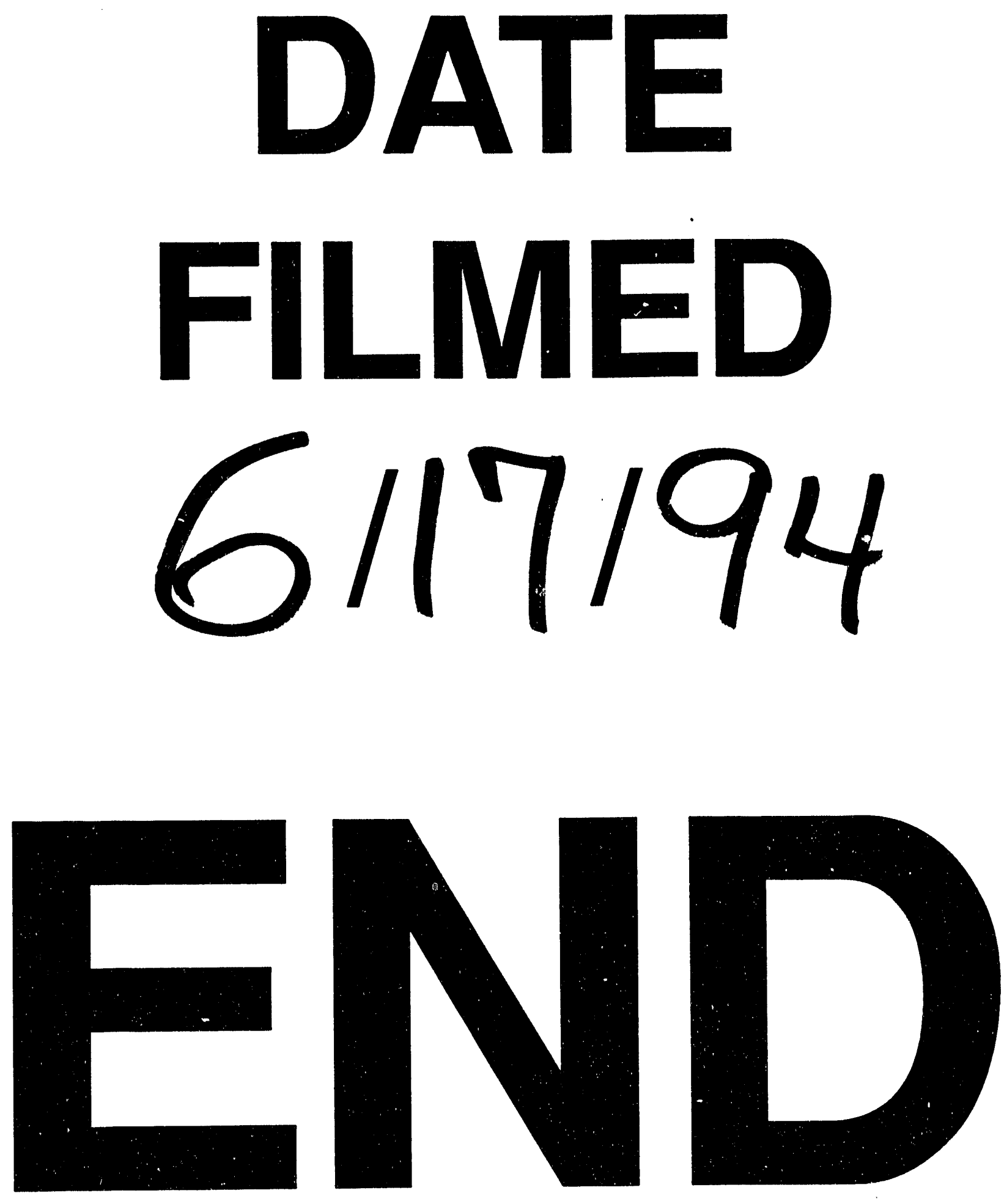
